12.

i

$9+1$

(x)

Sernere Otweines

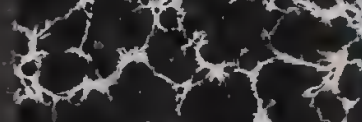

art

ton 5

$3 x^{2}$

$x \rightarrow \infty$ R

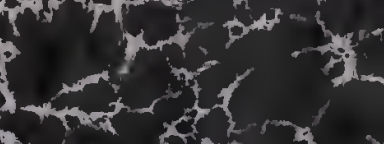

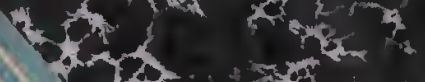

tet

$x^{2}$

S.

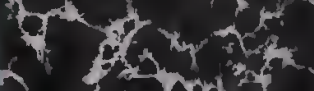

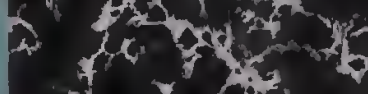

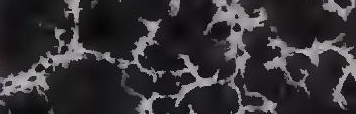
$x^{2}+x^{2}+x^{2}+x^{2}$ $\operatorname{lac}^{2} x^{2}$

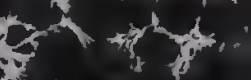

(t)

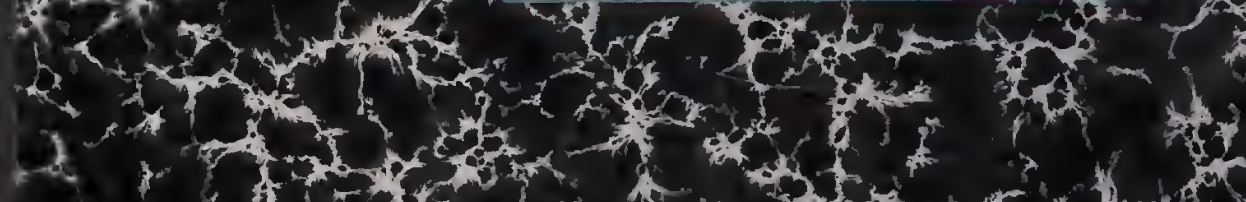

4 If mits

3.

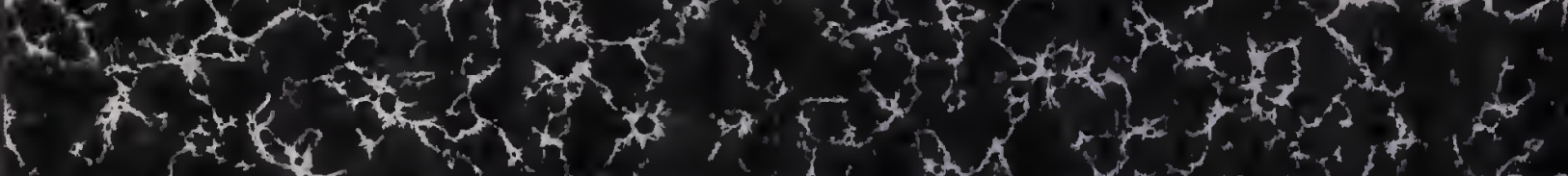

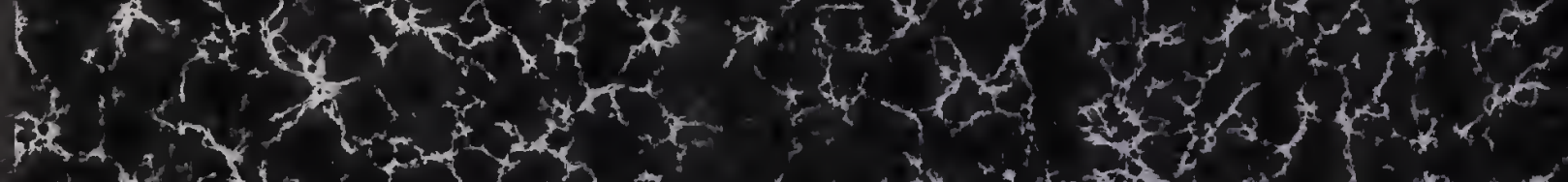
(n) 1.2.

(2. 



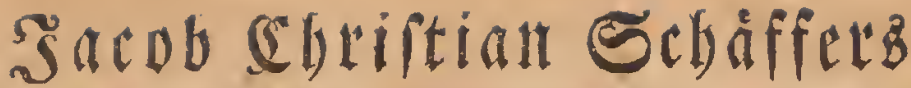

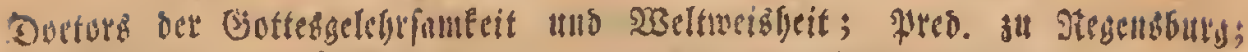

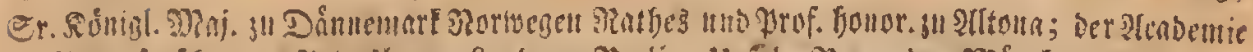

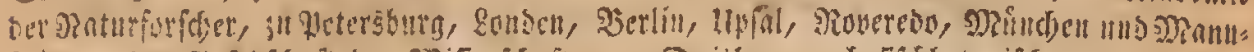

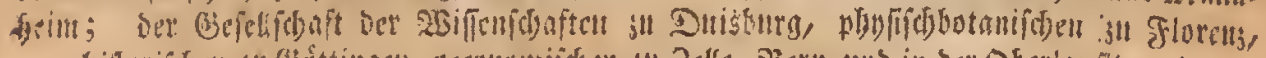

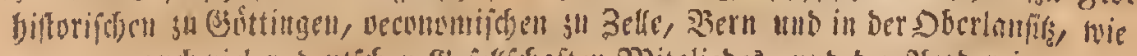

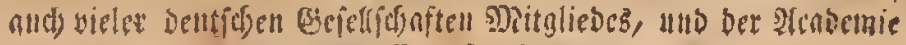
all Wnits Eurtefpurbentens

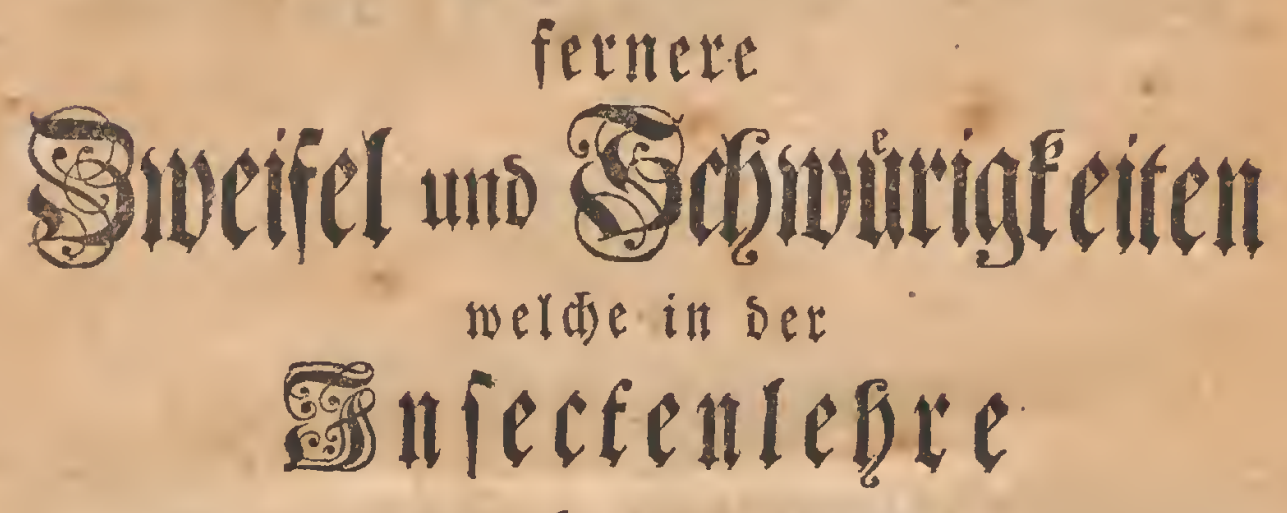

alltod volualten.

\section{Trobey zugleith}

anf oasjenige notbourftig geantwortet witb $\mathfrak{w} \mathfrak{a}$

in eillen bffentliden Slatte Diesfalls

ijt erimeth worben.

\section{ticbit eilter Gustemablen fupfertafel.}

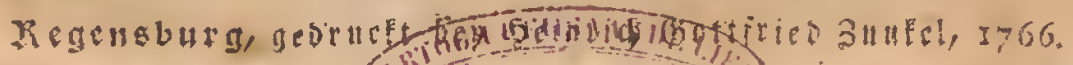

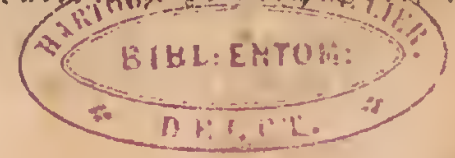





\section{$\mathfrak{D} \mathfrak{e t}$}

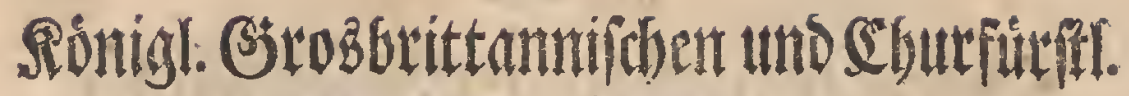

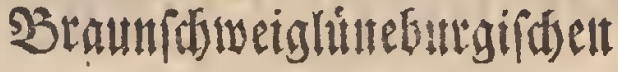

Eandwintbidaftigefellonft

$$
\text { कीlle }
$$

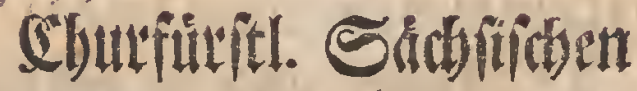

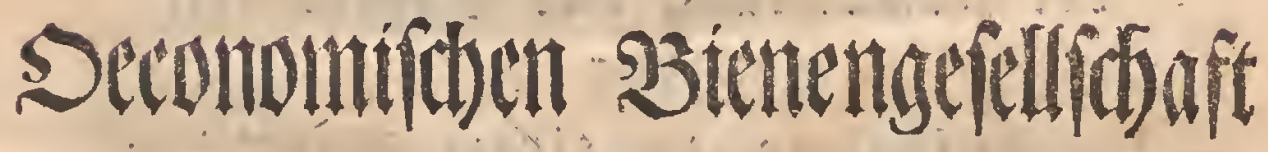
in

$$
\begin{aligned}
& \text { Det Oferlatfig } \\
& \text { ser } \\
& \text { Setzoglid dett } \\
& \text { Datticten Befrllifonit } \\
& \mathfrak{3}_{\mathfrak{H}} \\
& \text { Selutitád }
\end{aligned}
$$


Hito bev

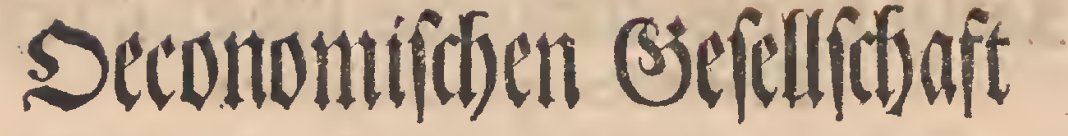

$3 \mathfrak{4}$

$\mathfrak{V} \mathfrak{P} \mathfrak{i} \mathfrak{l}$

wisntet

z"t cillent

dffentliate Merfutale

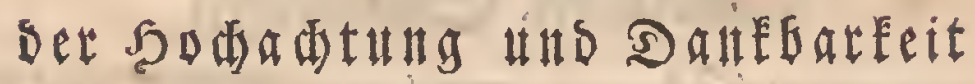

UDI

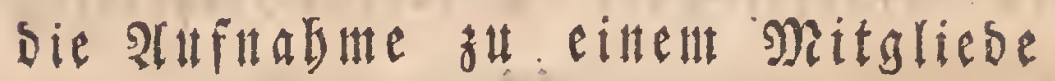
gegentwåtige כ̉átter

2iegensbuty,

oen 13 2uts.

1766.

Ser Derfaffer. 


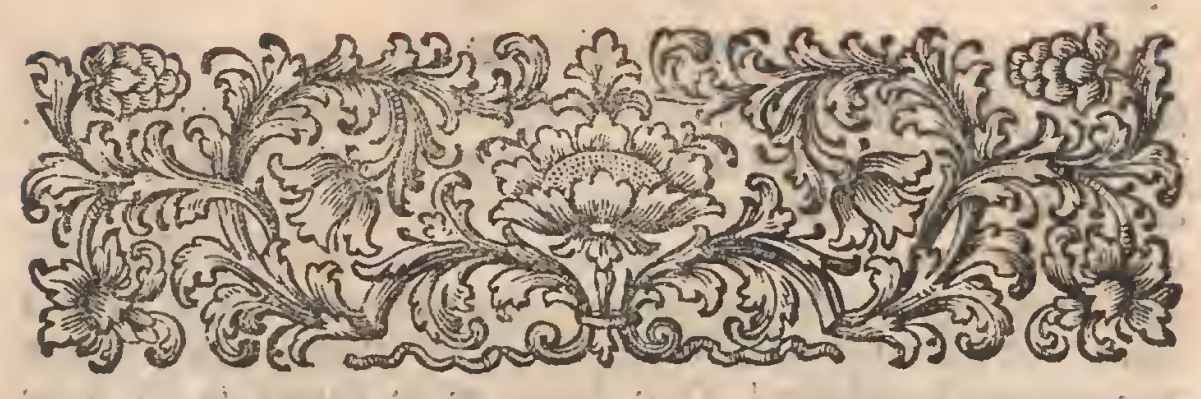

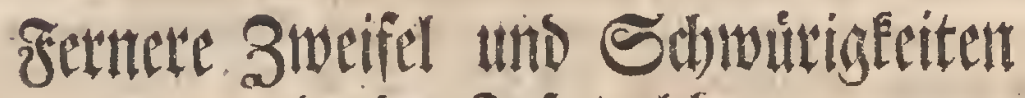 in ser Sinfectenlebre.}

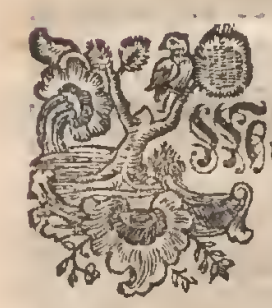

\section{Einleitung.}

Deb beliebsen who gemaimmithigen Sannóverifdyen 17 agajins 5.242. einverteiben laffen.

Eo bat dem Derfaffer biefes fồonen Xuffahes gefallen, darinnen meiner am Ende bes vorfien Jabres im Drucfe erfótenenen ämeifel uns

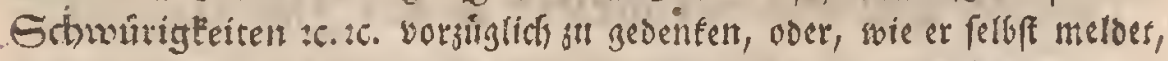

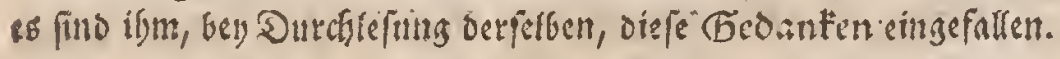

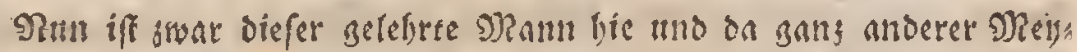

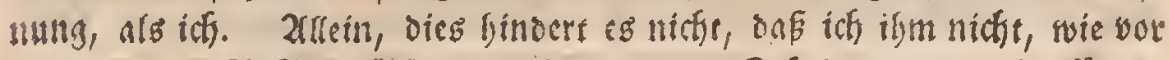

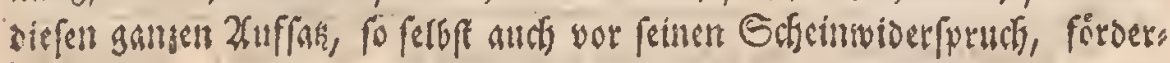




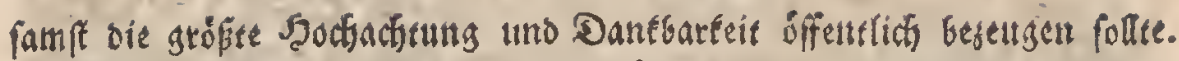

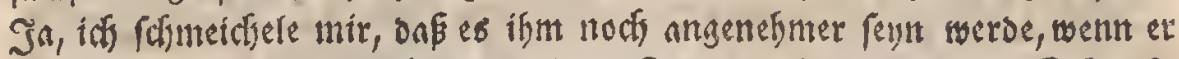

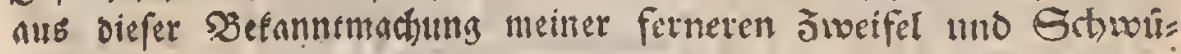
rigfeiten erfehen wirs, gth wa sor mellen Huterfucfingen, 2nmertun,

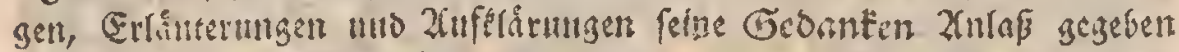

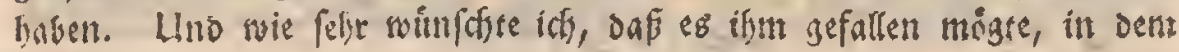

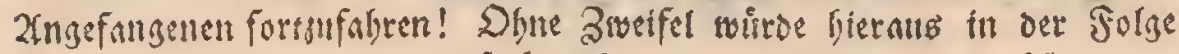

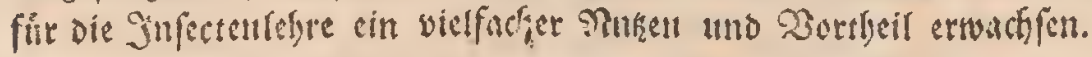

Soff babe mit alfo worgenoumen, fn biefen 23 listern dieienigen

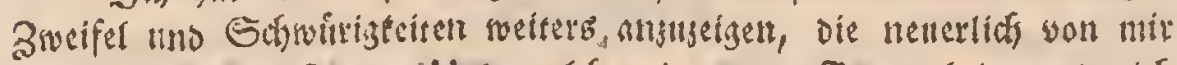

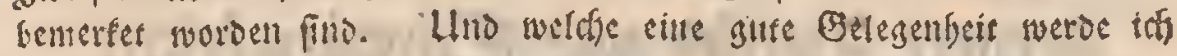
Giebey baben, - bie Groanten des Jern 23. in eine gename Leberies

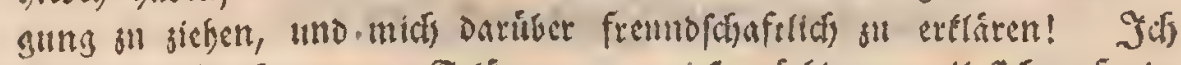

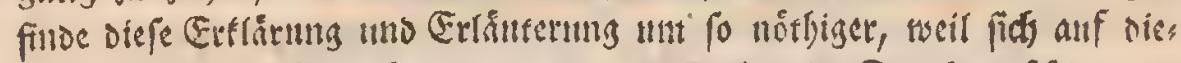
felben die gange Einticfinng meines mumeliro in Drufe erfolenenen cigentidjen Infectenwertes *) grinder, unb oline welche fich fievlich be Urfactie fordger Einridgenng nicht fo gleidy mogte einfelgen, nody ges birig bentheilen, rapent.

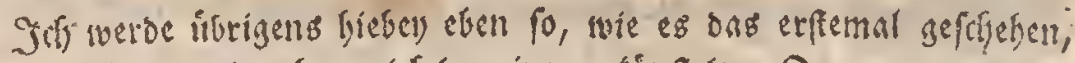

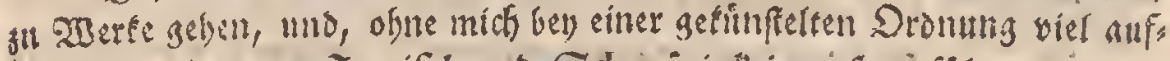

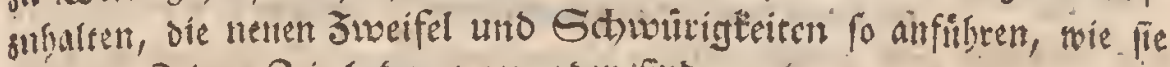

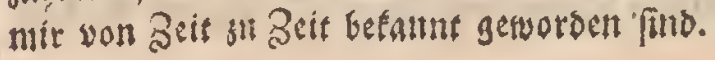

\section{§. I.}

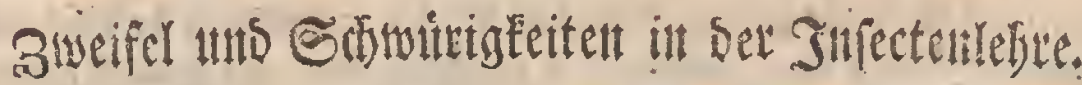

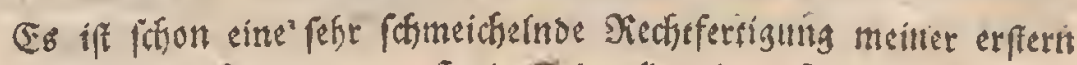

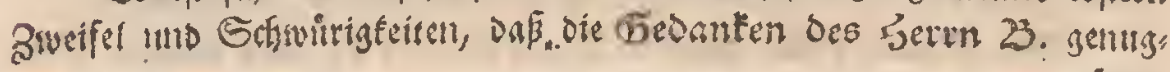

*) Ic ones infegtorum circa Ratisbonam indigenorum \&c. Vol. 1. Pars I. 2ubbilbuntent

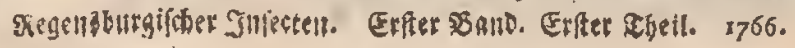




\section{es 繁}

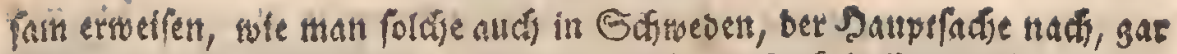

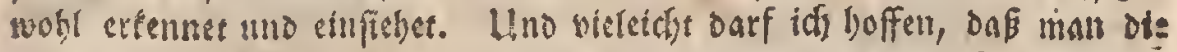

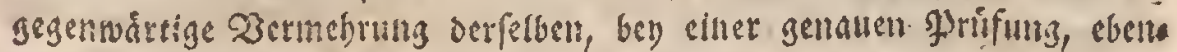
falls der Erfahrimg vollfommen gemáf, mo vor nicfits meniger, als übern sriefent, ereldiren iverde.

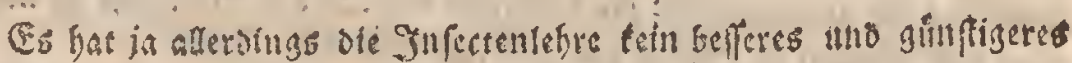

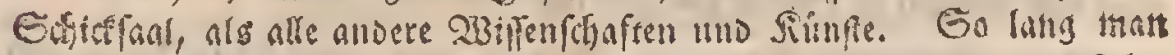

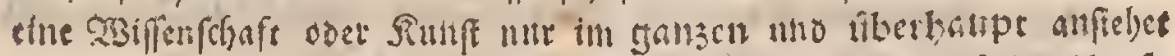

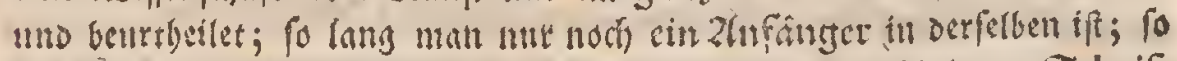

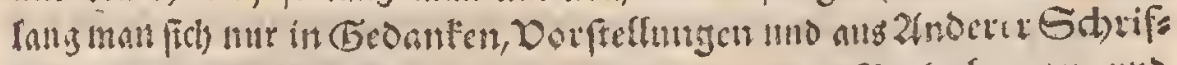

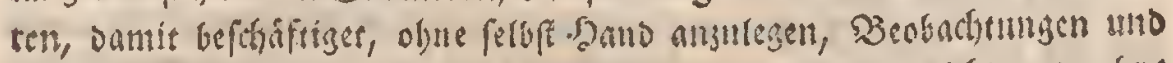

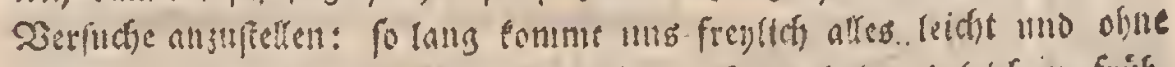

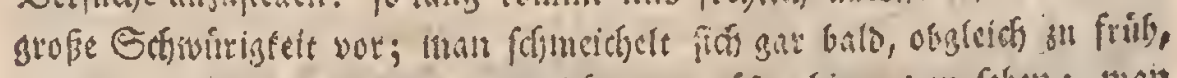

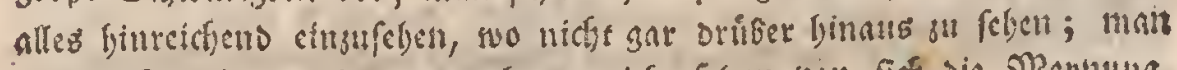

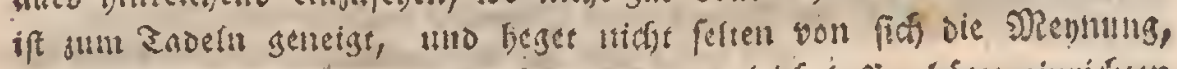

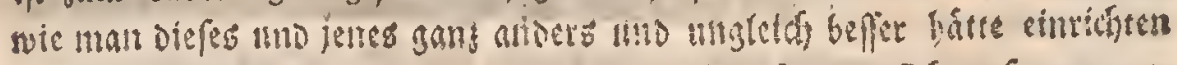

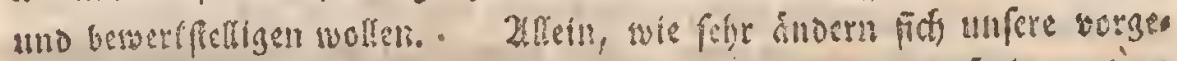
faften Nownungen, Geoneten mo, Urtheile; ment man anf elne ondere

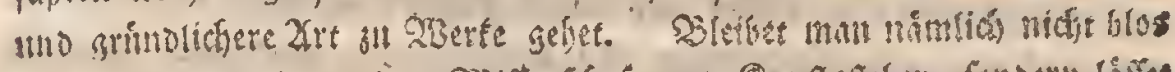

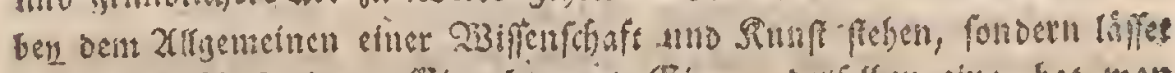

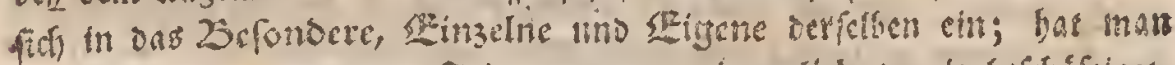

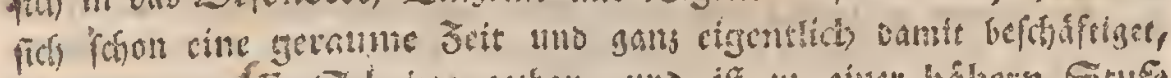

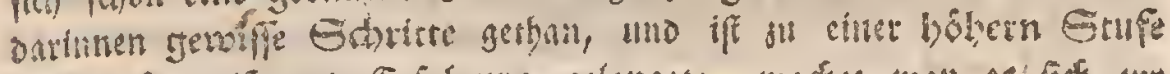

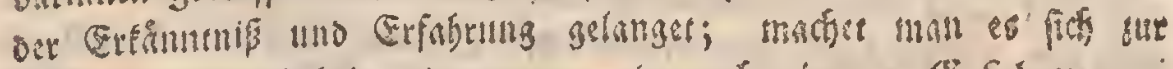

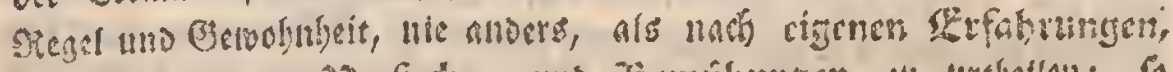

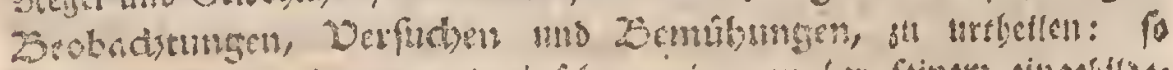

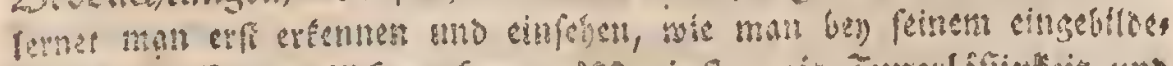

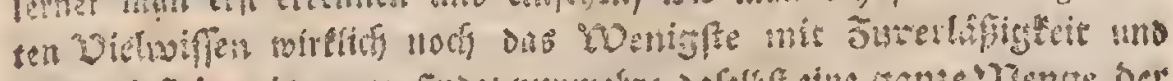

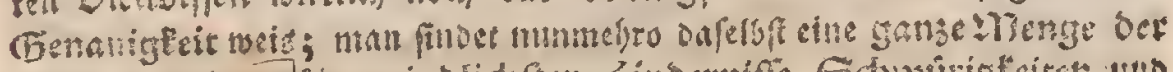

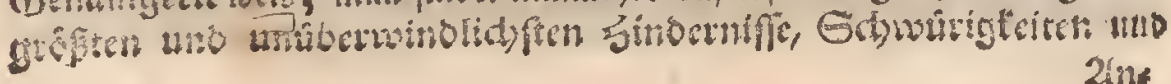




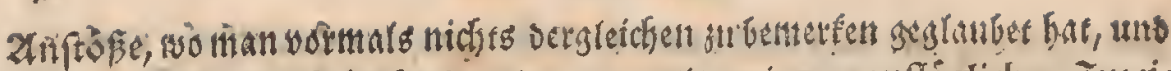

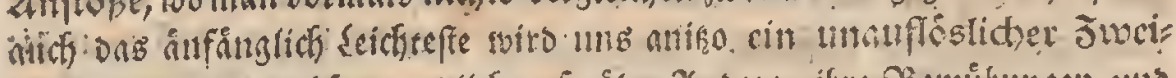
felatnoten; man boret cnolich anf, liber Zndere, ifre Bemibungen anto

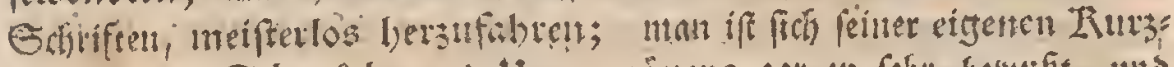

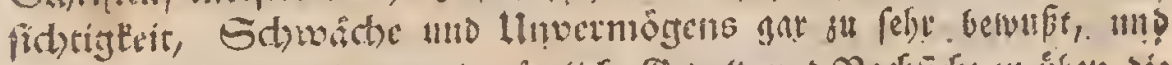

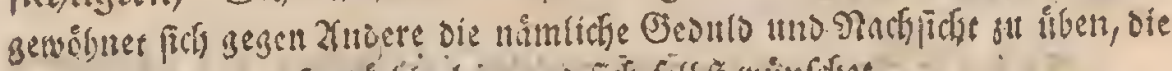

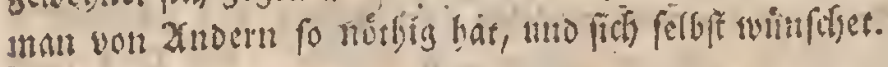

Sermuthlidy wird eb thir feine Sefjande feyn, went itf midf von sent

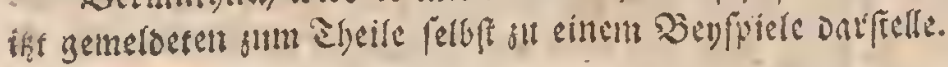

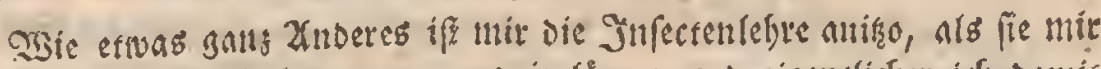

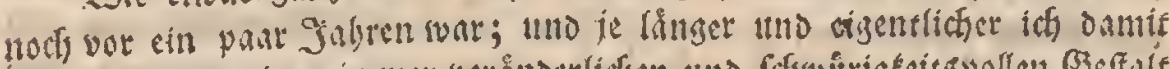

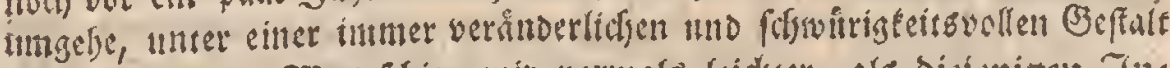
zeiget fie ficf. What fotien mit vormals leidjer, als dicfeniget Tthe

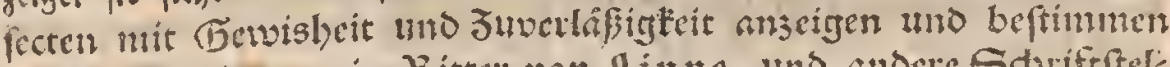

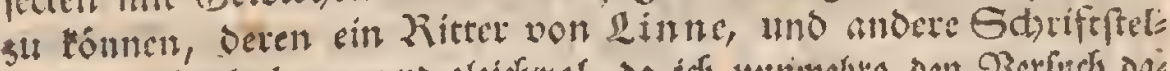

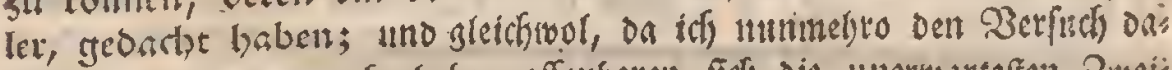
mit in Btopan gemacht babe, offentiren fich bie Inerwarteften Bueis

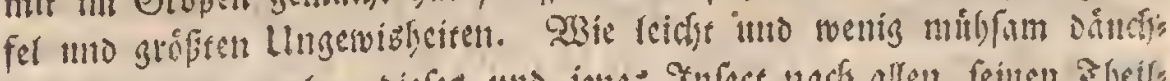
tete es mir vormalen, biefes tnto jenco Jnfect nach allen feintel Elyeits

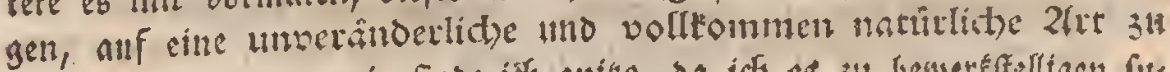

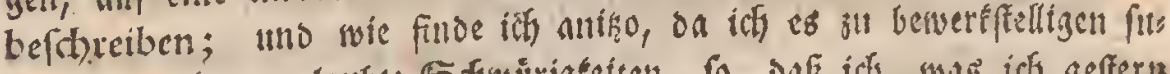

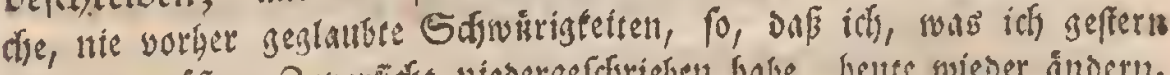
unif ber grofiten Buverficht niedergefdrieben habe, bente wieber änocrn,

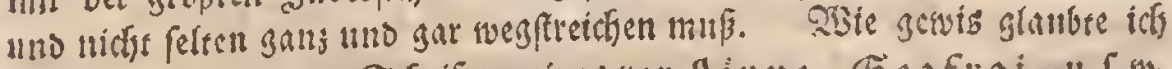
chemalen, ons in Den Gefriften cines von Linue, Geoftoi, u.f. m. wo nicht bie tteiften (B)

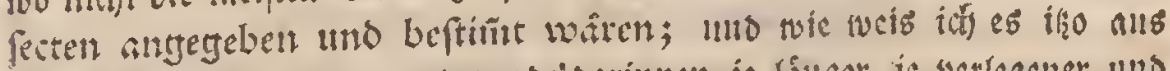

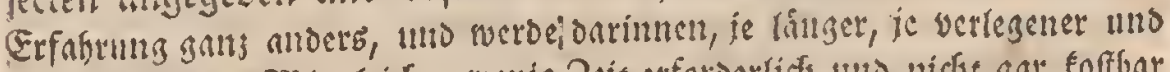

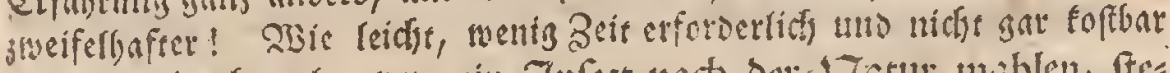

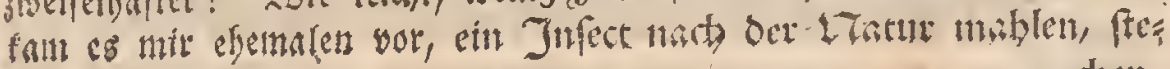

st)er. 


\section{ero}

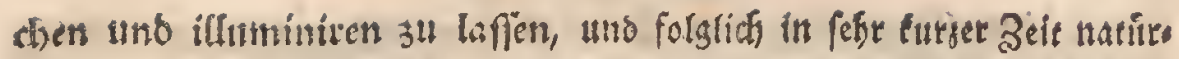

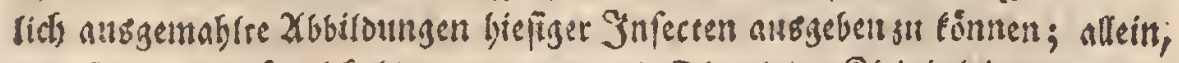

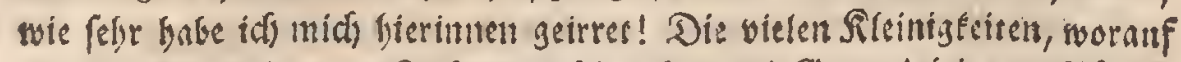

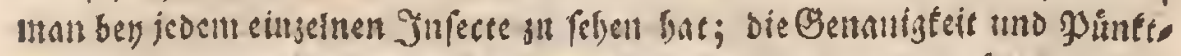

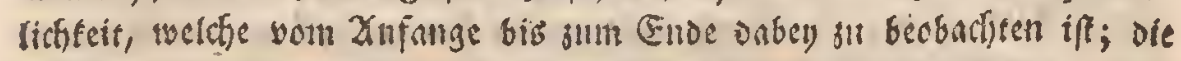
beftämige 3ergleidjung mit andern fhon vorgefommenten Yufecten, und

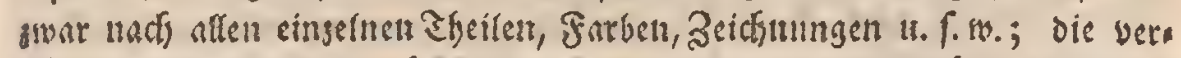

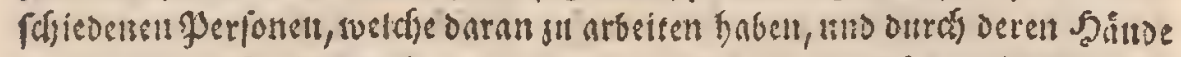

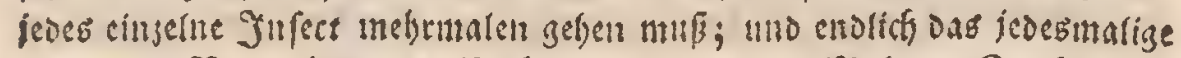

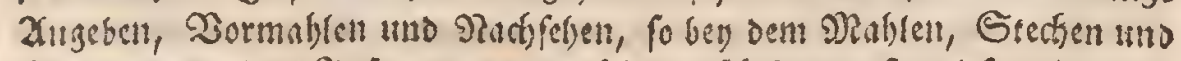

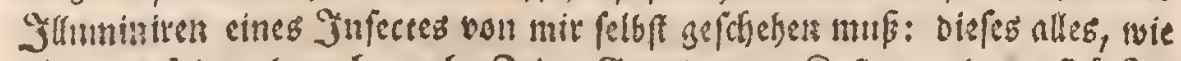

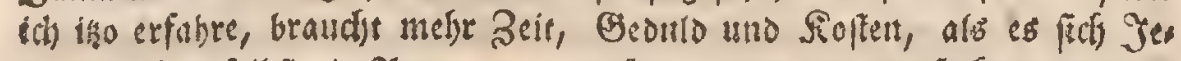

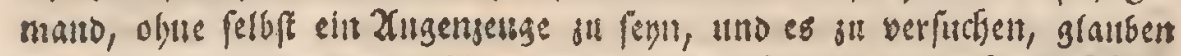

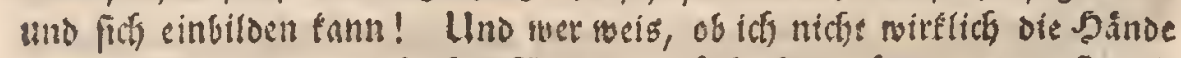

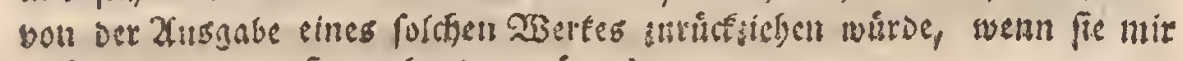

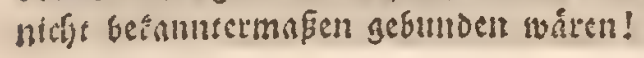

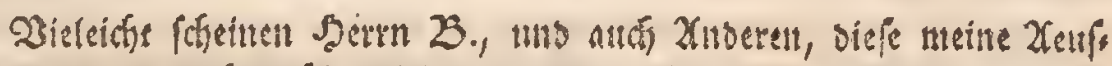

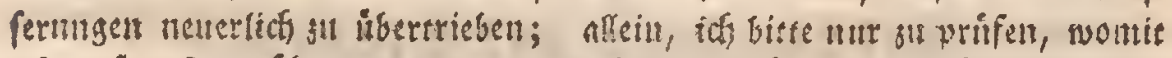

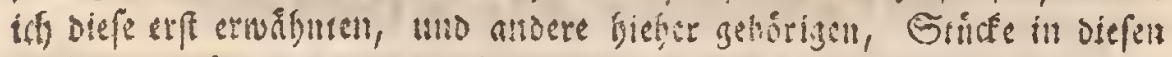

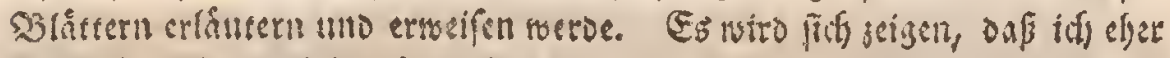
atr wenig, al6 ju vier, gefager babe.

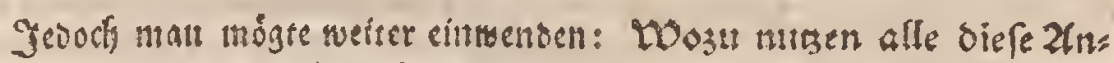

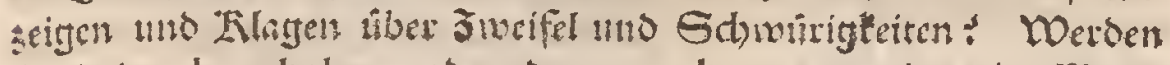

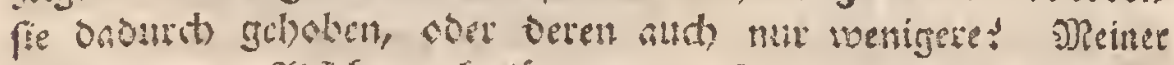

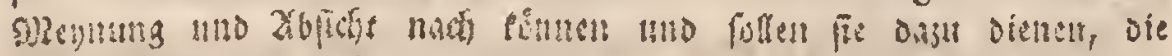

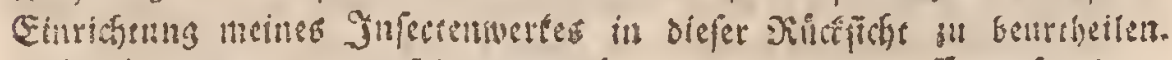
Soinfchet man an beinfelben mandjes anders und beffer; fo glanbe

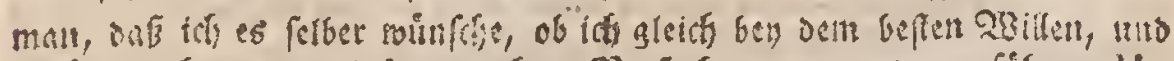

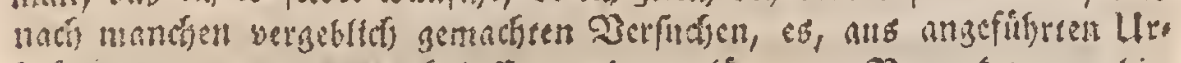

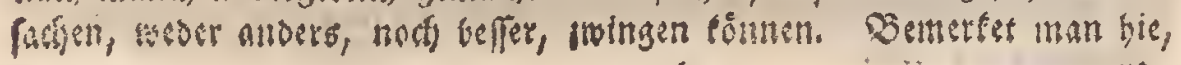




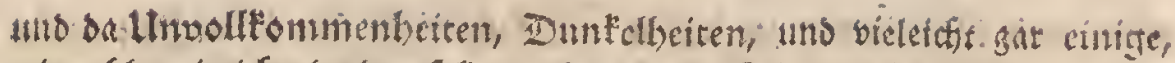
wienofy, wie idg glanben folte, mix geringe; febler; fo dente inan, one, nad angesciger Befdaffenlyeit der Sadje, dergleichen bels einem fols chen Werte faft unvermeiolicts finb. Finder Jemano balo an oer 3eict)= mung, balo an ber Grelling, balo an der farbc, n. f. w. etwas aubats fefin; Der felje erft die SRanr, und smat an verfefiedenen Jnfecten von eis nerley Guttung, mact), ehe er fich ibereilef; und wenn er alsoenn glcichrod

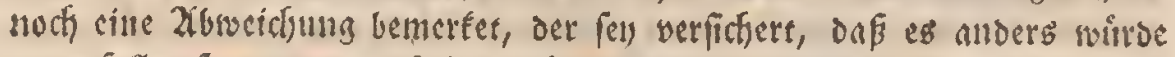
ausgefallen feyn, wenn ich.feleft batte Dabler, Rupferftedget, Jfluminift,

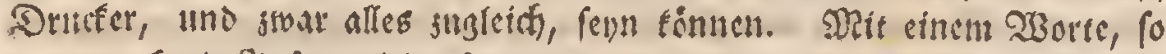
lange noris die Infecsentelye fo iff, wie lie hentigen rages ift; fo lange iffe

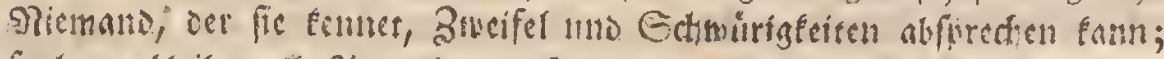
fo lange bleiben alls. Xusgaben derfelben tinvollemmen, wno bevinfen der

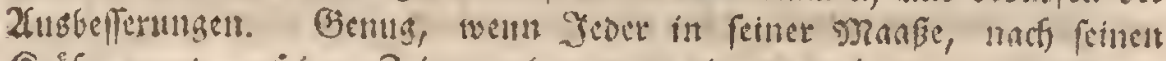

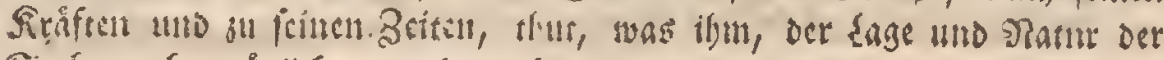

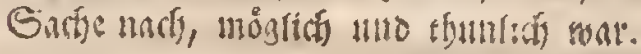

\section{$\$ .2$. \\ echrgebittio uto elaffent.}

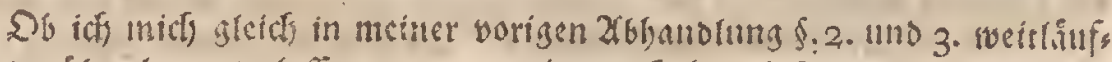
tig Dariber beranes:laffen, was es mít. Den Rebrgebändon mo Clafen= eutheilungen oer Jufecten dermalen vor eme Beffuffenhei babe, uno de Lirfaden anjeiges, warum idf theils dab Linneifte Eyfem nit

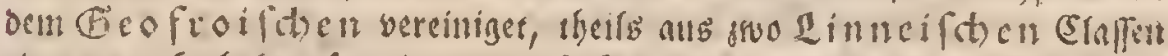
eine gemacht babe; to erinnert ood 5 err $\mathbf{3}$. ongegen juscerley.

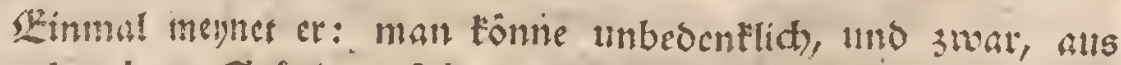
beygebrabten Giviten, fict an dem Linneifden Syfeme be:

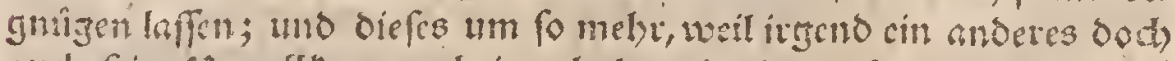
culds feine Itnvolfommenbeiten baben werbe, 11 . f. w. Sobann fefiet ar an meiner netren Claffe oct 5 d) uppenlo fen (gymnoptera) verfitiebenes aus.

23ด 


\section{ars}

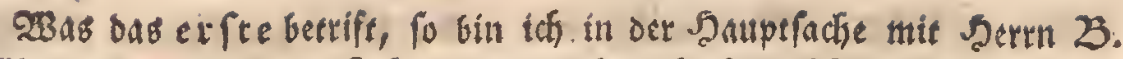

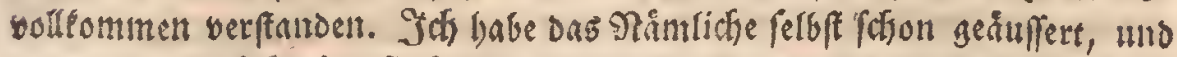

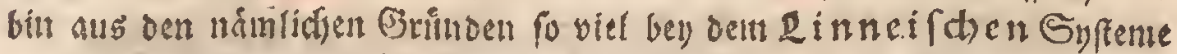

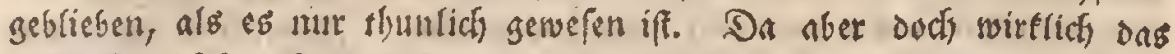

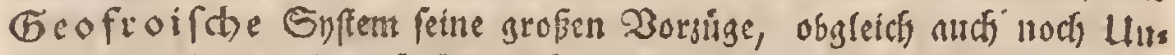
volltommentietten, bat; fo follte icls glauben, es forme weder grope Ders

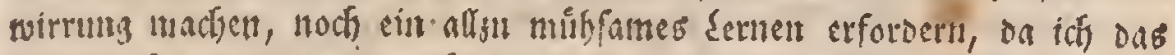

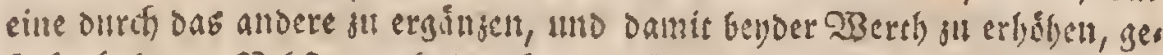

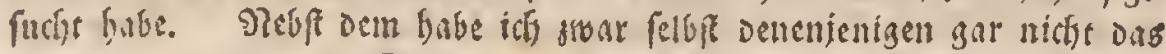

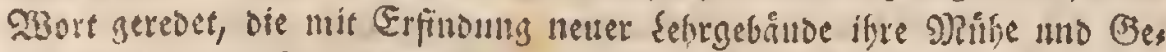

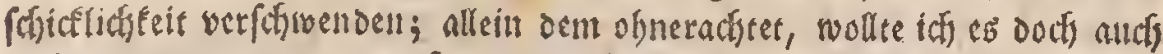

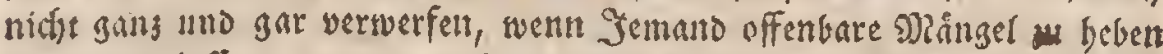

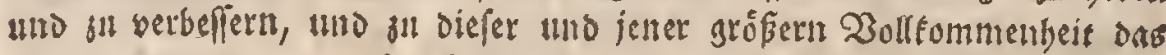
Eeinige bensutragen fich wirde alngelegen feyn lafen. 5 Ranctier wirft

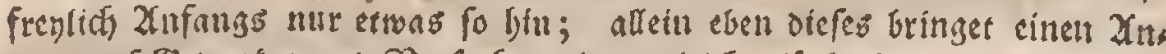

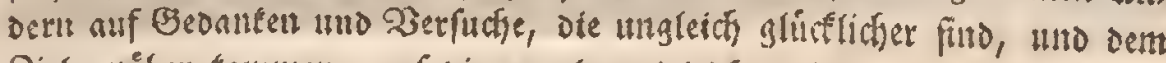
Bicle náber tontmen, auf die er aber vieleicht, ofye jenten 30 orgånger,

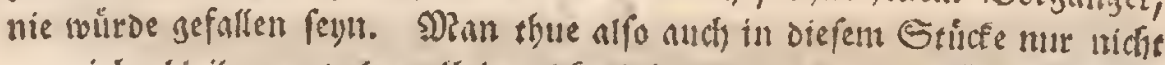

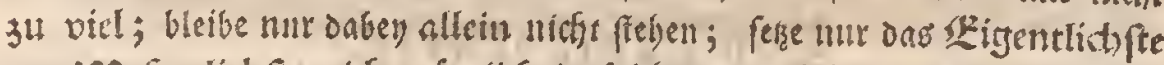

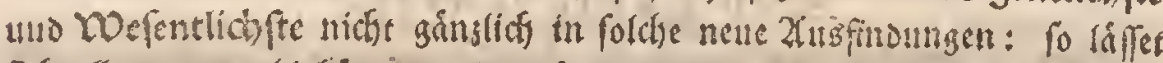

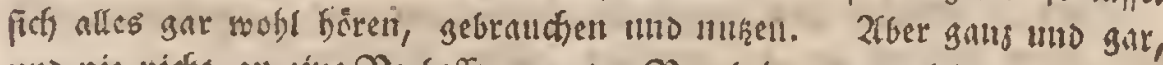

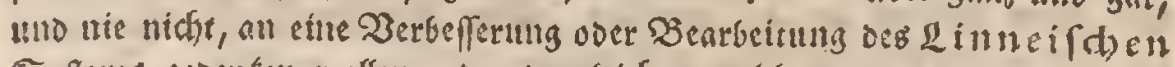
Syftems gedenfen wollen, oder derzleichen wobl gar bor umméglidf und

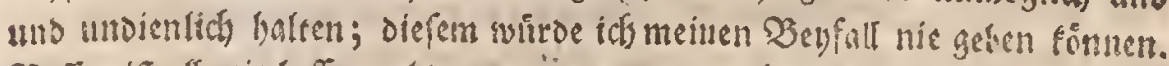
Beffer iff alfezeit beffer, alo gut; wienn man auch gledd) fanjfan, auf vers

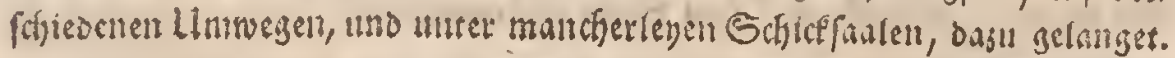

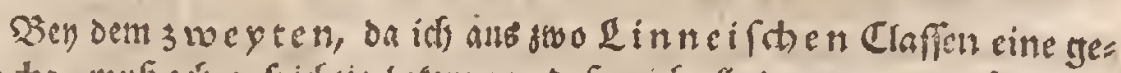

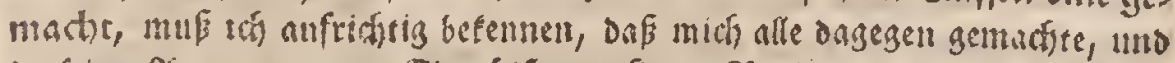

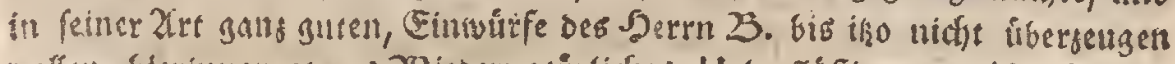

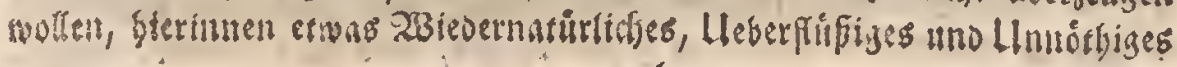




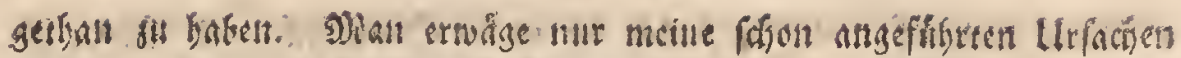

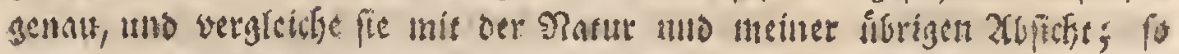

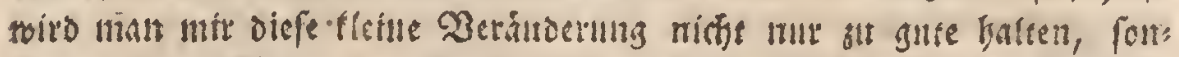

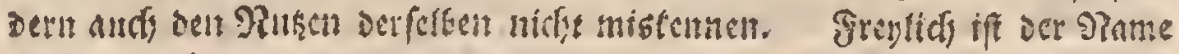

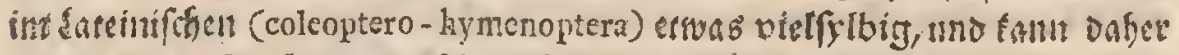

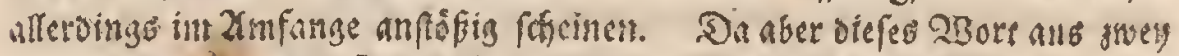

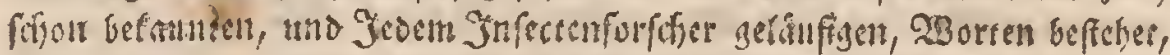

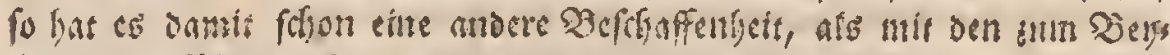

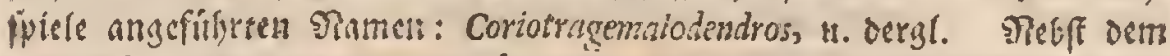
babe idf in feibft Den Plamen bemiptera gugleids mit bebbehalten; mu

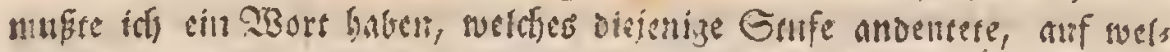

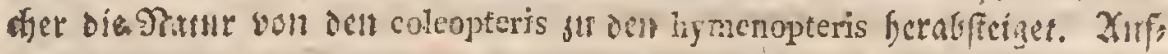

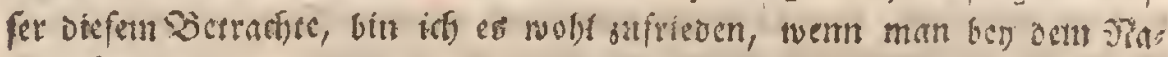

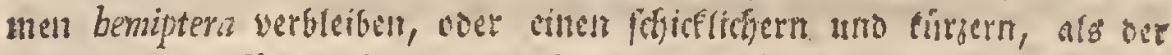

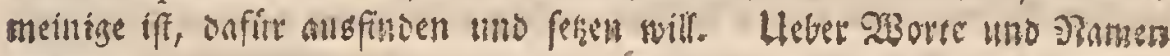
wetbe ich uie firsiten!

\section{S. 3.

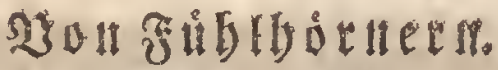

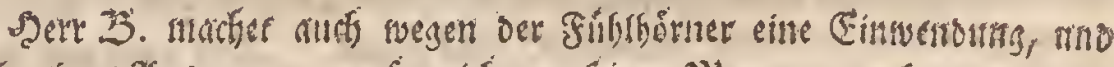

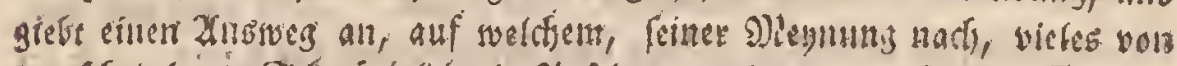

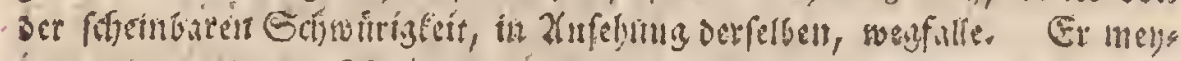

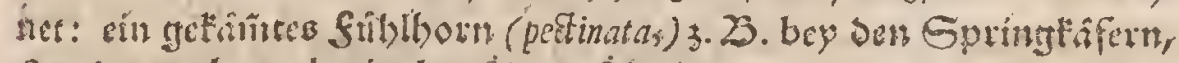

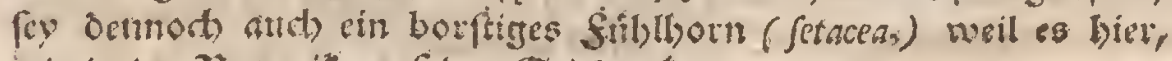
wie in bet 23otante, anf Den Stiel antomme.

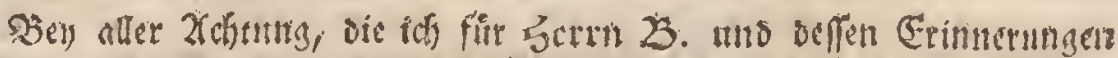

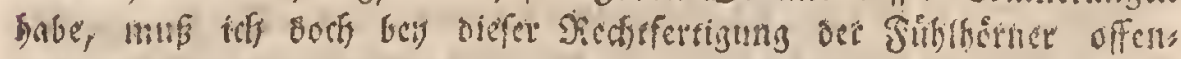

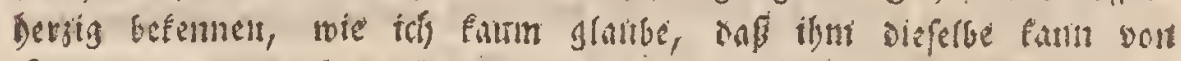

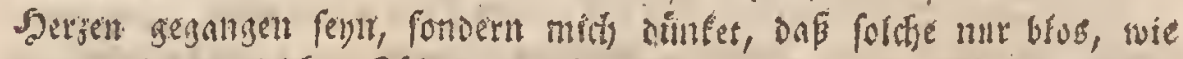

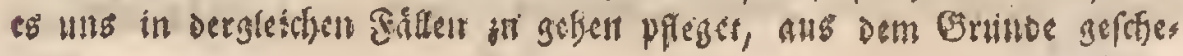




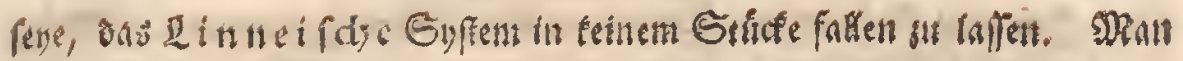
uberdente unir biefes.

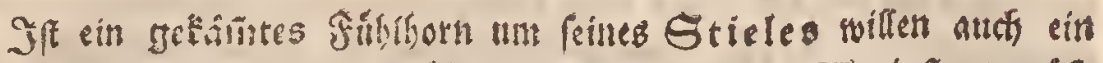

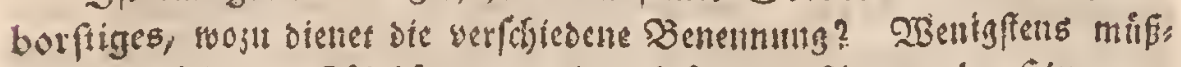

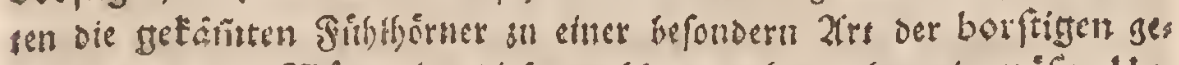

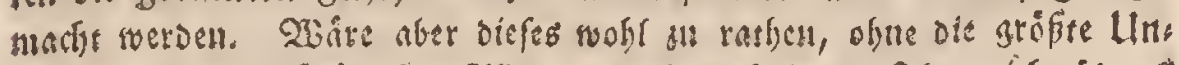

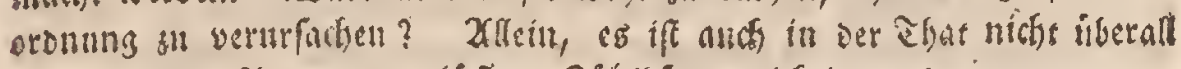

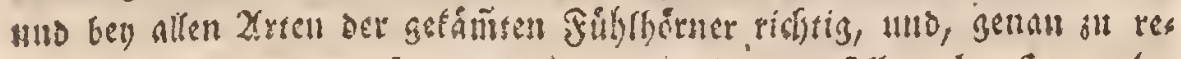
Den, in der shan gegrindet, Dak oer Stiel oufelben borftenartig.

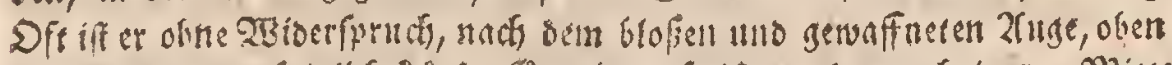

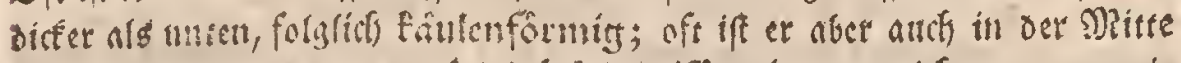

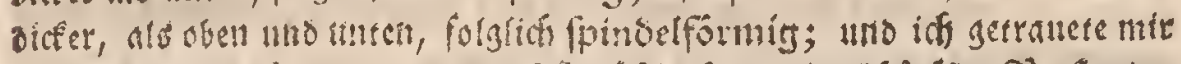

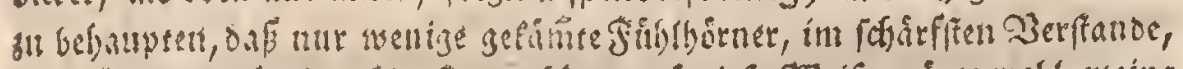

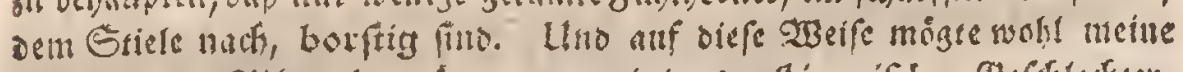

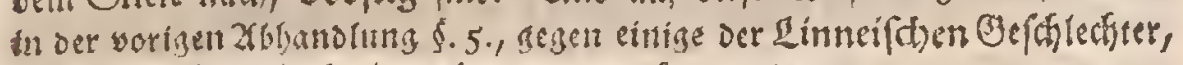

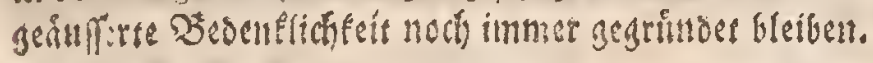

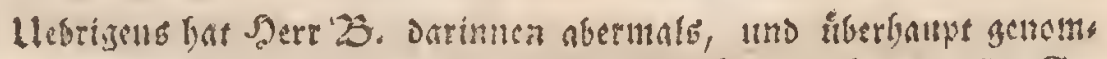

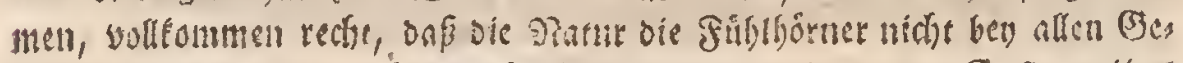

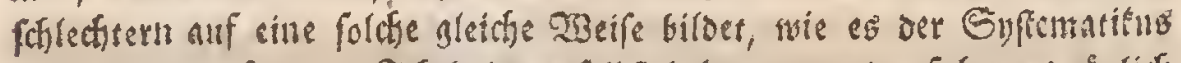

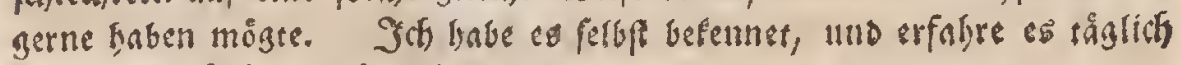
Bfters tutro liantriger, als mir fieb iff.

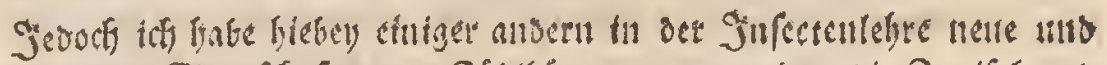

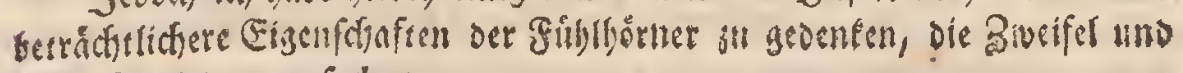
Schwirrigfeif wetarrfachent.

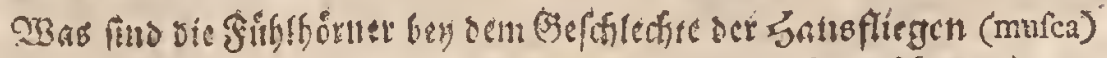

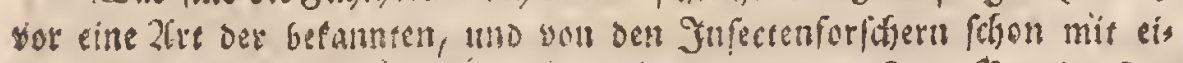

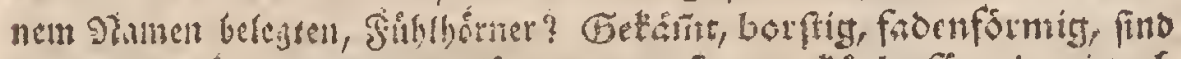

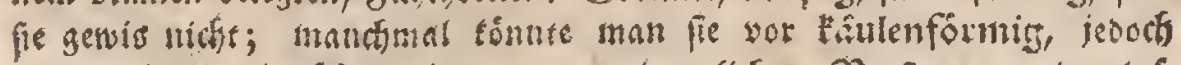

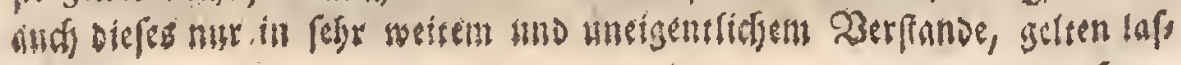


fett. Tob habe fie in meiner Einleitung fpadelformig gentunte. Nidge, als ob ich oie/e Benennumg, ifnen volftommen angenteflen erachtete, fon

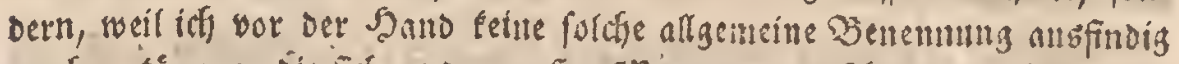
machen finnen, oic fich ju oer grofen sRenge ber verfichievenen Zrten bies fer fpadelformigen Finthörner bequem gefflicfet bätte. Denn diefé fpodolformigen Fübrgorner, oder wie man fie fonft nennen will, gehen

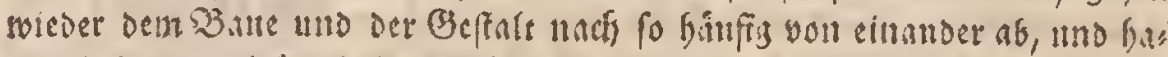

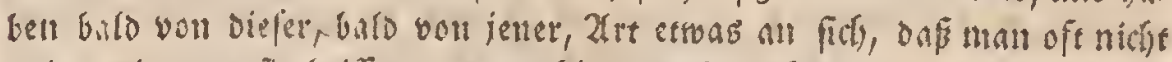
wets, wie man fie beiflen, oder sobin mail fie rectinen foll.

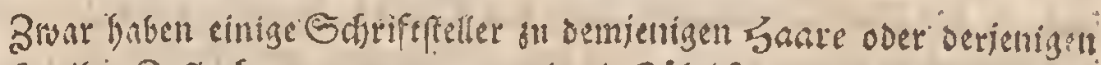

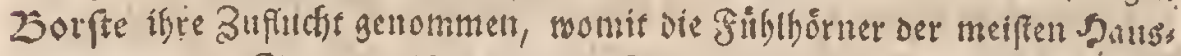

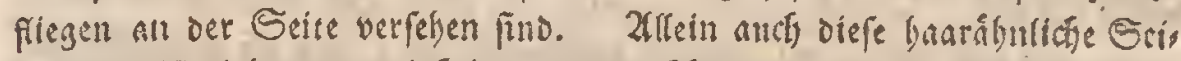
tentorfte ift viel su inaunigfaltíg mits verfofieven seftaltef, als inf oaber

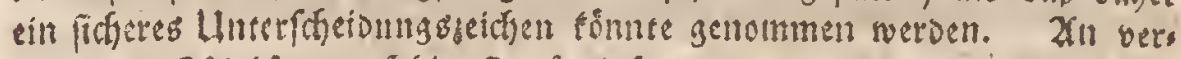

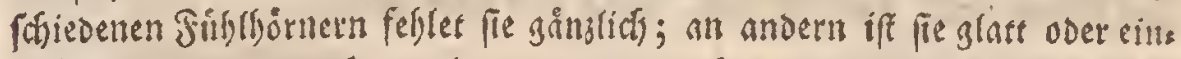
fach, an andern rands ober baarig; uns tidfs feleen find and oiejenigen Seitenborfen, die dem bloben Xuge glatt fdieinen, unter der 2ergrölfes rung rand und banrig. Do idh mir mun gleich viel Brifhe gegeben, dies

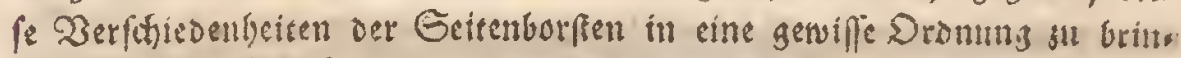

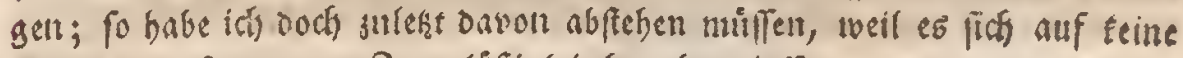

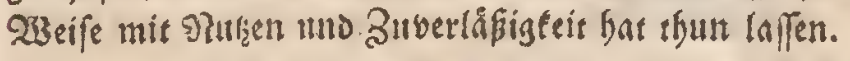

Uno was folf ich, felbf von den befannten, und ifren eigenen Pamen: fefon babenden, Jubblbornern fagen? Dुbe verfegen ift man nicfye oft, an beftimmen, ob diefes Fiblyorm borftig, oder nicht viefmetir fascnformig; ob jenes tâlenformig oder nidit vielmebr fpinselattig; uno ob ein orits

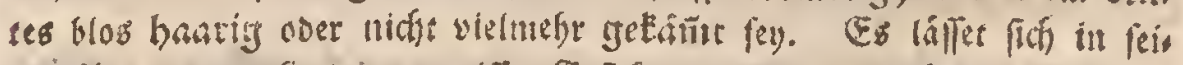
ner Xrt und undj einem gerwifen Befichtspuntte, in ber That oft bendes

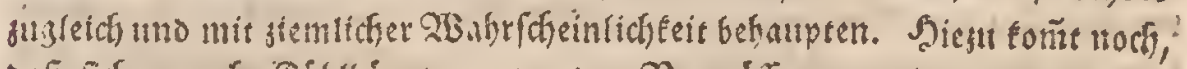

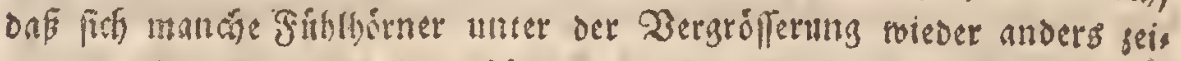
gell, alg fie dem blofen Zuge fdefnen? Man mus alfo in 93 aljtheit of 


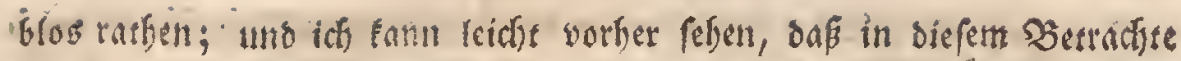
mandjer audh mit nit niche sufvienen fern swirb, neen ich biefes uno jes

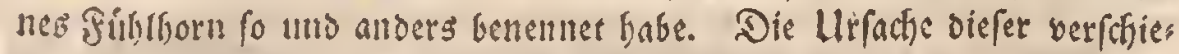

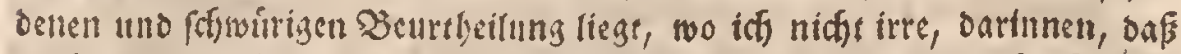

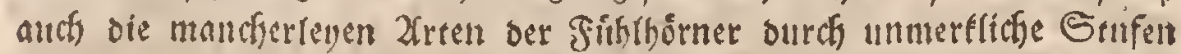

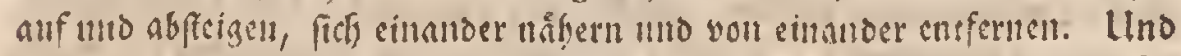

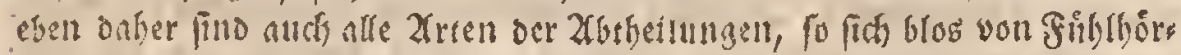

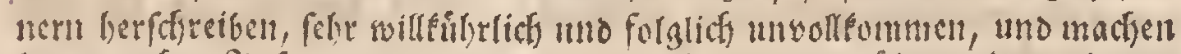

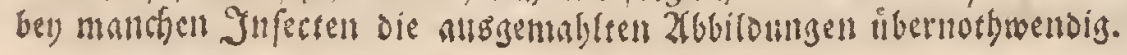

\section{\$. 4. \\ (3) forterber mo diattingen.}

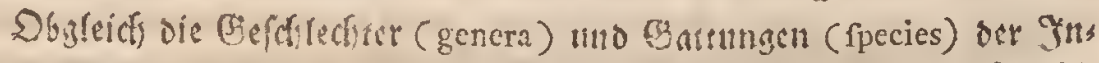

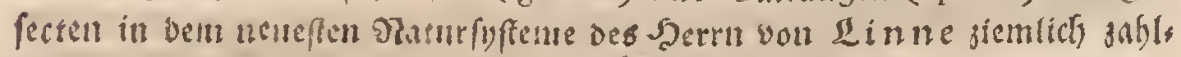

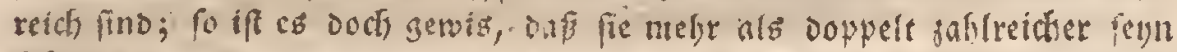

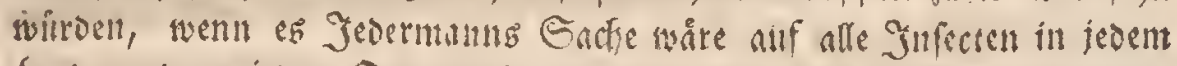

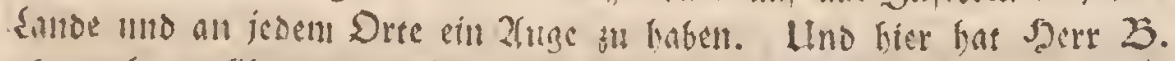

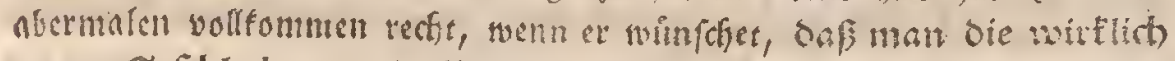

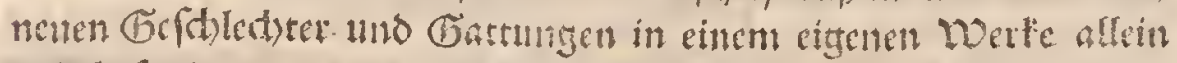
thno befonders susgemablt liefirn modtre! ic. 2c. Jefl habe diefen

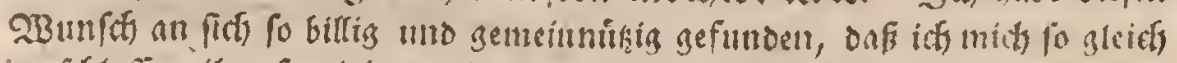

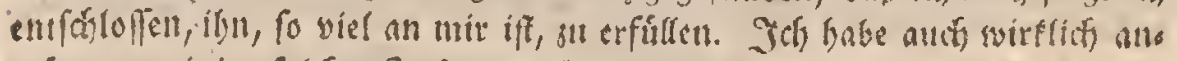
gefangen, einige fordjer Jufecten, fo mir nenteplich ju Ge fitchte getonmen,

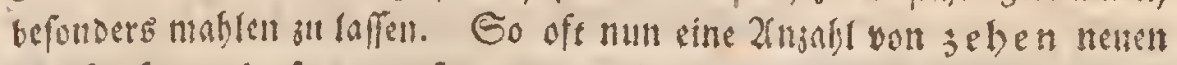

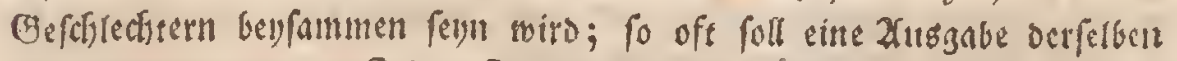
folgen, und bamit von Zeit an aeit fortgefalyen werben.

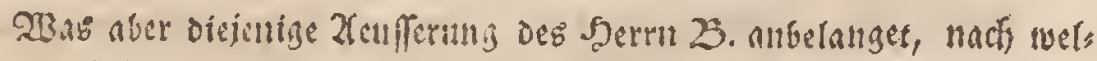

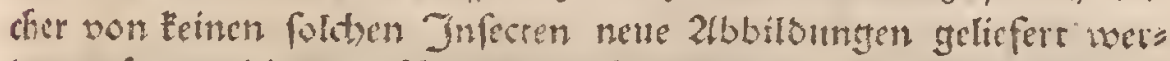

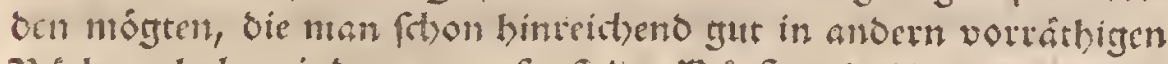
23 tidberin babe; indem man fonft den Lianfern toptbare Dubletten allf: 


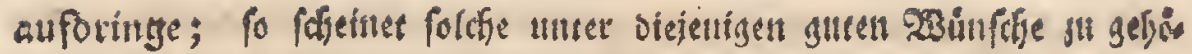

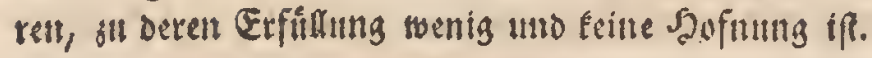

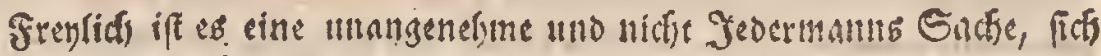
meforere topbare aberfe um wentge Darinten fid befindendon uenen

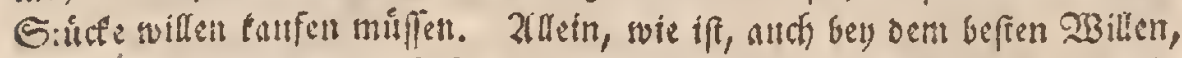

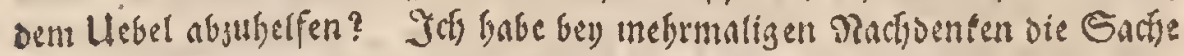

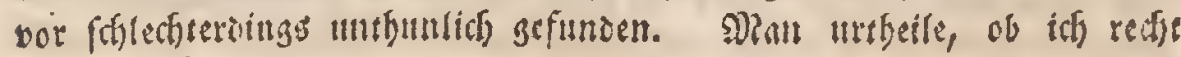
oder unreclit habe.

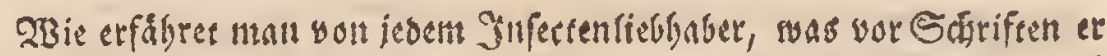

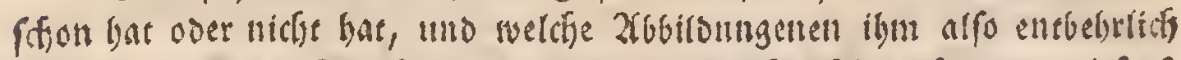

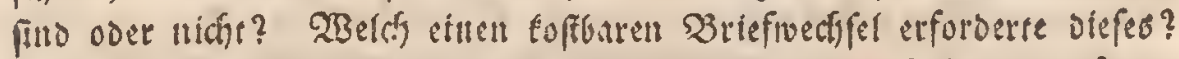

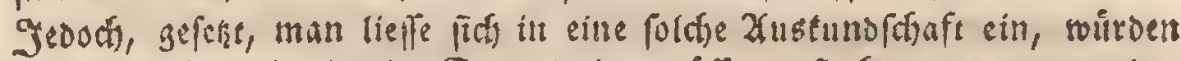

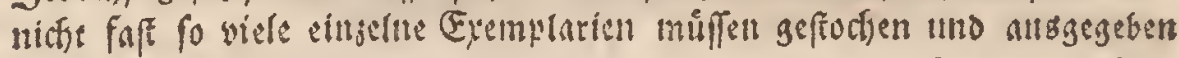
serden, als cingeine Jufectenliebfaber gefunden werben?. Der eine whirde bie Sherianifden, ber andere die Roefeliften, uno oer brifte und viert: wieder andore 2 bbilomnget, verbittell. Ilno was poirde derienige oajk fagen, bet fich nodf gar feilles volt allen fofon borbandenen Jinfectelts

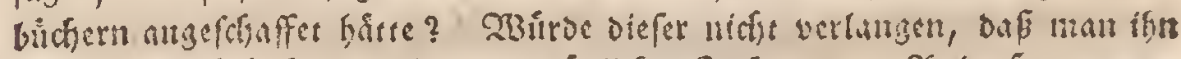

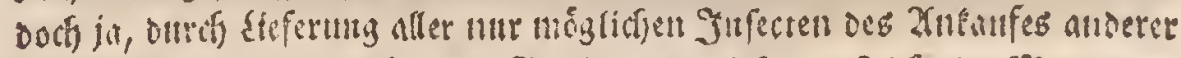

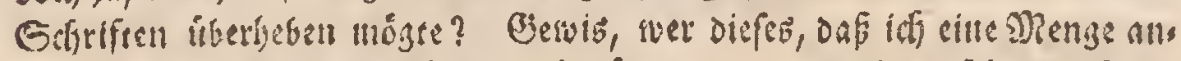
berer Bedenelichfeifen nicfe gedente, iberleget, der wirb einfefen, daf der

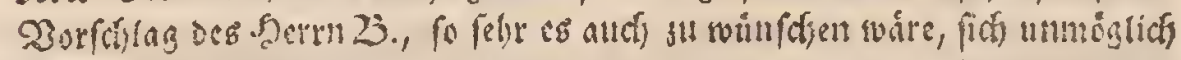

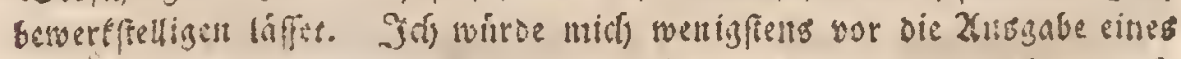

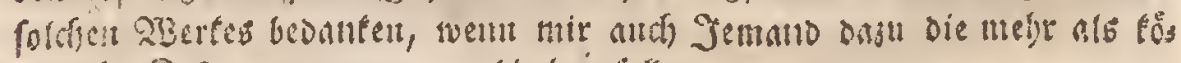
niglidge Soften stum vormib anbietben follte.

Dicfes aber, ghube idf, ift rhuntich und ratbfam: baf man anfange,

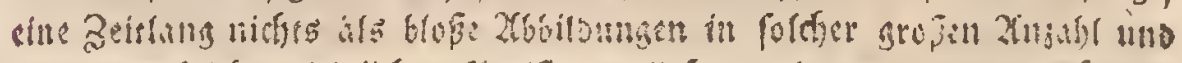

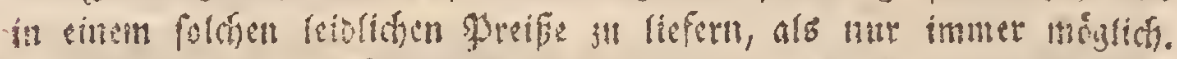

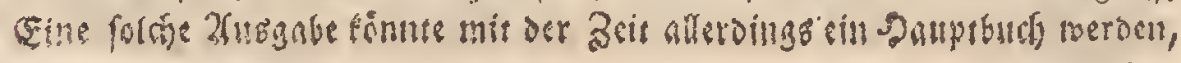
anto, 


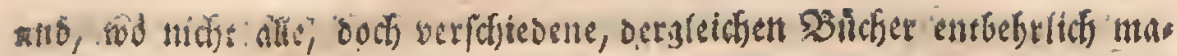

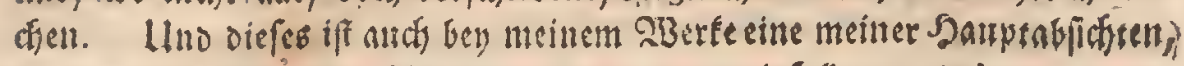

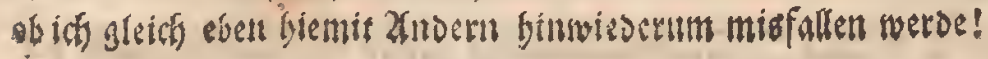

\section{5 . \\ Tamilient.}

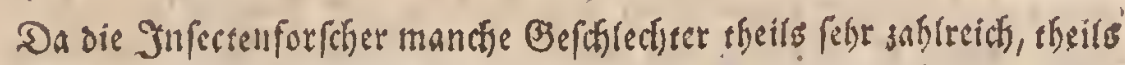

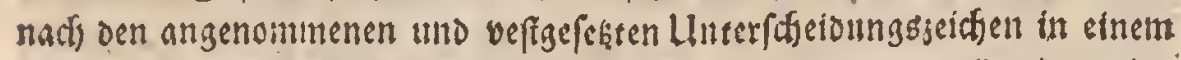
unt bem andern Gtirfe afweichend, Befunden; fo baben fie alletbings eine

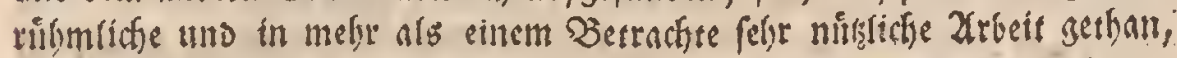
ous fie dergleichen. Oefchlectyer nsieder in gewiffe Famtlien abgetheiles.

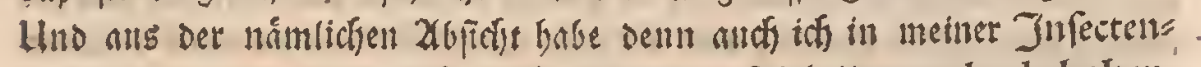

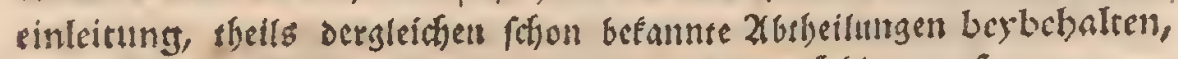
theils fordfe bie uno oa vermelyser, theils, wo es nothis gewefen, neue ges.

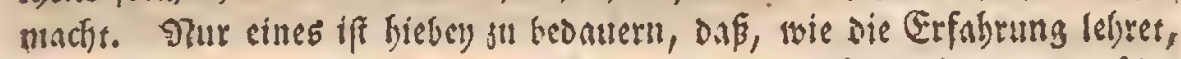

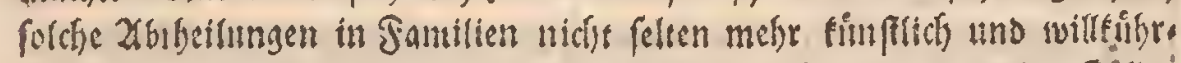

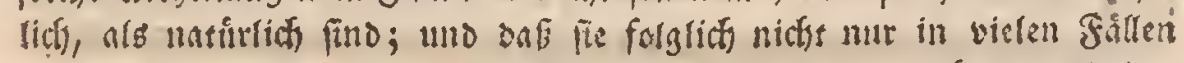
manchem Brweifel und mandfer Edferirigfeit, fondern auch wicoerbolen

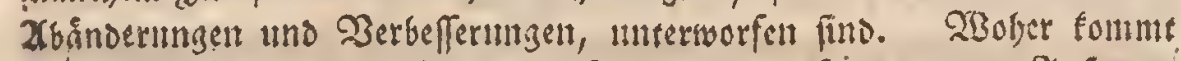
diéps? Ulnter andern daher, weil oft eilne eben gefundene netue Jufectens

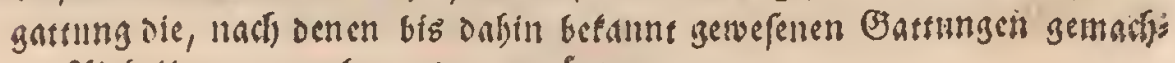
se, 2lorfeitung vermebret oder gar ăndert.

Stieju formmt nodf, on mancte Infectengaftungen in lebendigen

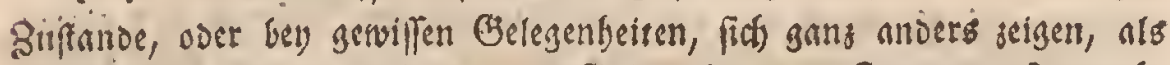
in todecn Buffande uno bey andern Belegenhefien. Ferner, daßs manche

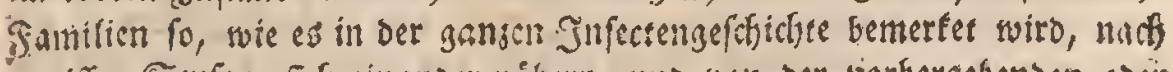
geviffen Stufen, fich einander nithern, unto wan ber vorbergethenden oder thichfolgenden fannilie dergeftalt vicles geineinfames baben, daf man jie

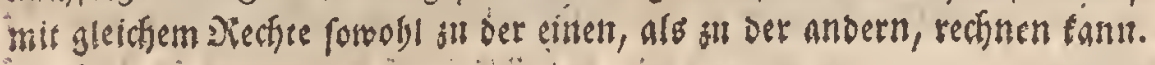




\section{4}

*e

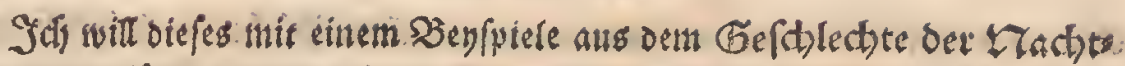
folter erweifen.

Ith habe itt tteinet Infecteneinlettung biefes Oefchlectie math oet

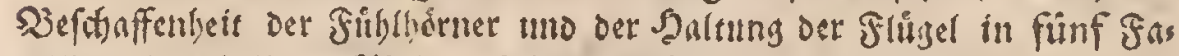

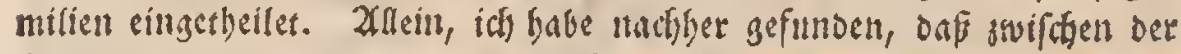
Fantile init abbangenten mo offenen Flityeln, nocf oie, nls eille cis gene und befondere cinsuricten, mit flochen ober fachanfiegenden Jifis gett. Denn es ift geivis, Daf mandje diefer sactstfalter, mit gefimmen oder borftigen fiblhimern, die Flïgel, genall sll reben, fweder abbangen Infeit, noch woflig ausgebreiter halten; fonoern gans flach tragen. Go

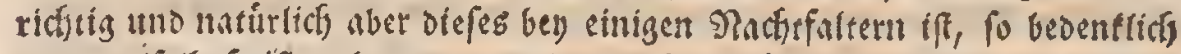
unb sweifelbaft ift $e_{b}$ bey andern, in dem fie folche sut einer Beit fo, tho sut

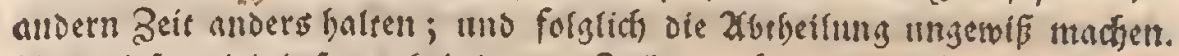
Uno diefes gielt infonderfyeit in dem Falle, machoen mancher SRadiffalter im lebendigen oder tooten aufande angetroffen wird. Sent tch babe ges funden, daf bie Flingel vieler S?act)tfalter, weldfe ifnen, fo lange fie leben, flad) anfiegen, fich in Bode in abbsingenbe ju verwandeln pregen.

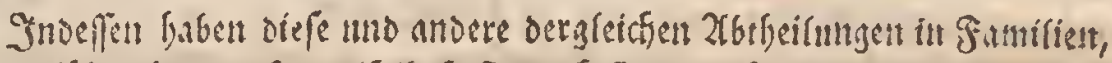

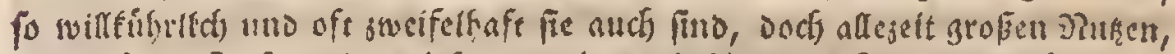
weil fidf eill Jufect, bey ofefer oder jener beftimmten Familie, leichter fint Den Ifffit.

\section{6. \\ Spielatelt.}

Te unlängurer eg ift, daf jede bautung der Jufecten ibre eigene,

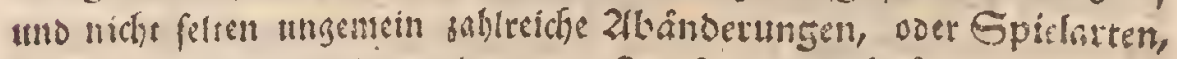

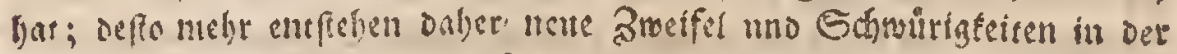
Jufectentebre. SBoher socis tof es gewif, Dafs diefes und junes mur eine

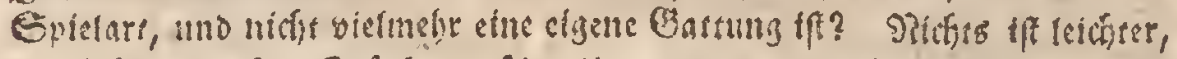

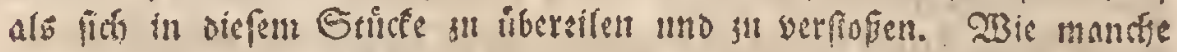

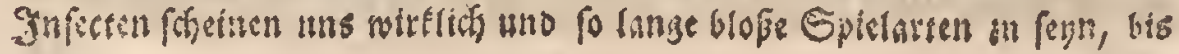




\section{Ner}

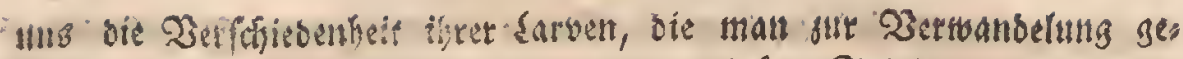

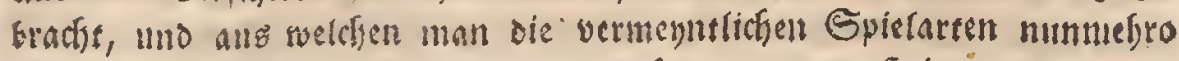

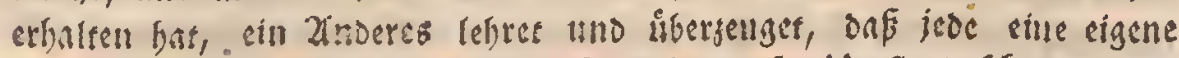

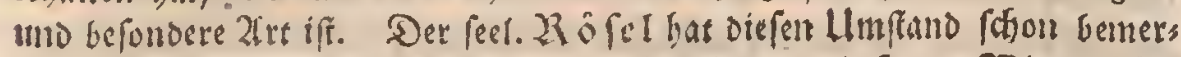
fet, uno, Dnvon in feinsm 233 erte einize Benfpiele getiefert. 2Bie zweifers

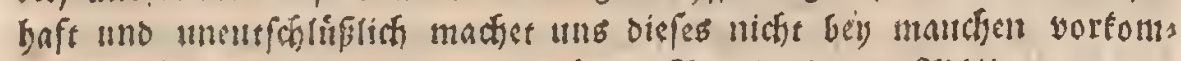

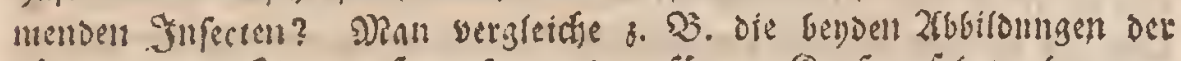

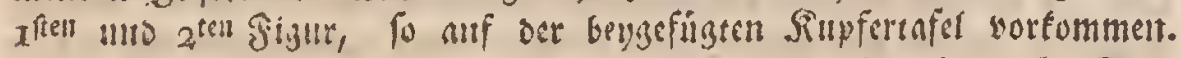

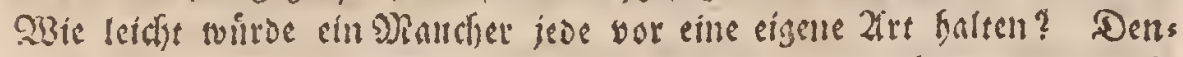

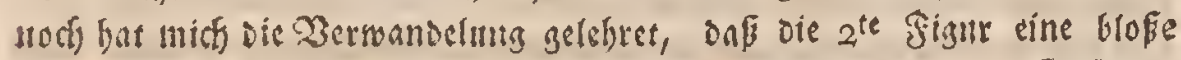

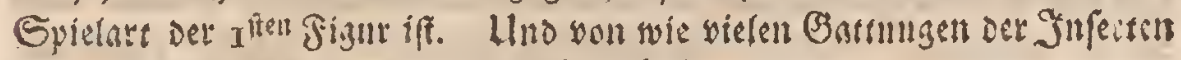

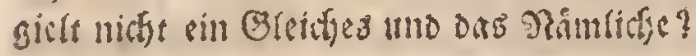

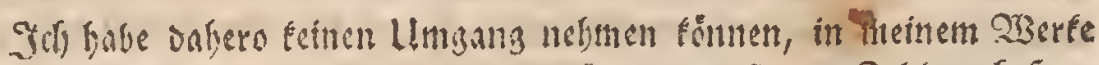

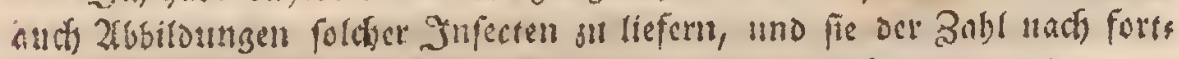
laufen 3 sa lafin, bie vieleicht mur Spielarten, vieleiclit nber nuth eigena

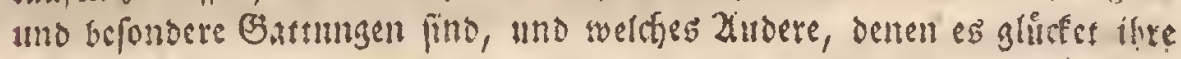

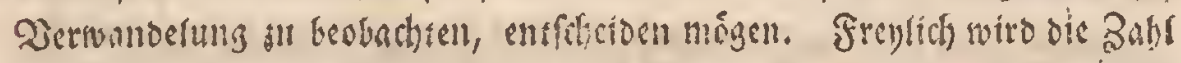

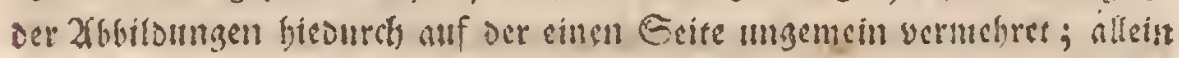

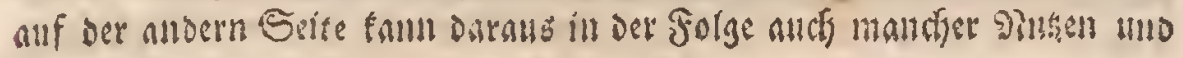
Zartfeil erwatjjan!

\section{5. .

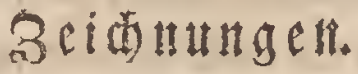

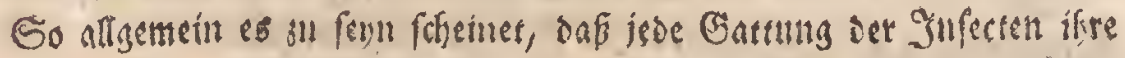

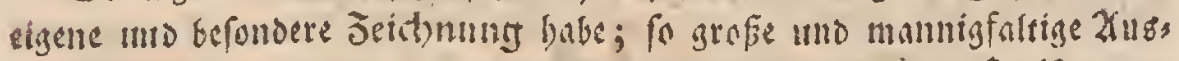
nafimen bat deefer Sal in Der giatur und Erfabrumg. Errcife, Puncte,

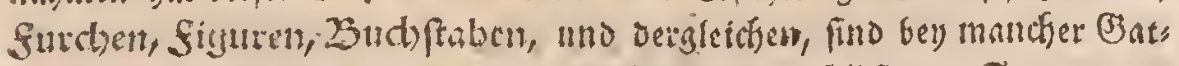

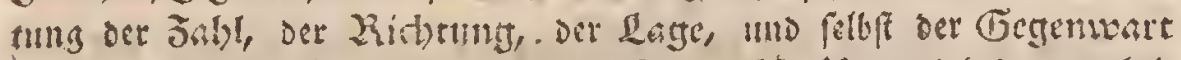

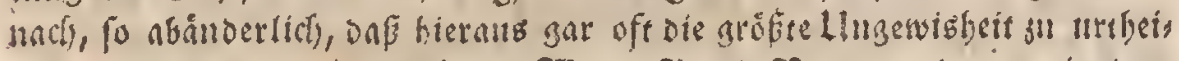

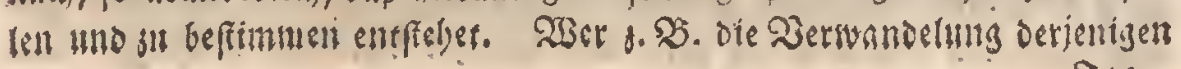




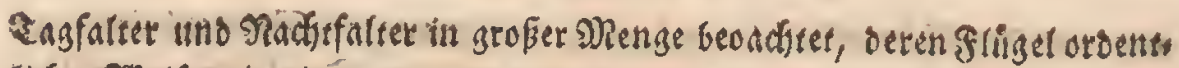

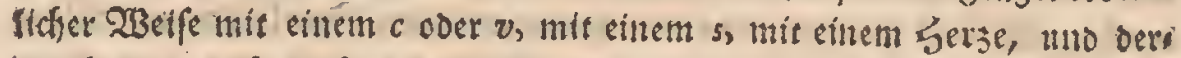

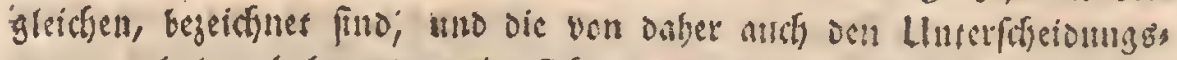

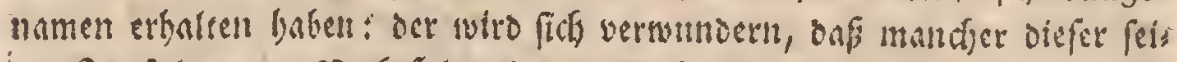
net Engfalter uno गradiffaler faum eill PRerEmat vou dem Budffaben

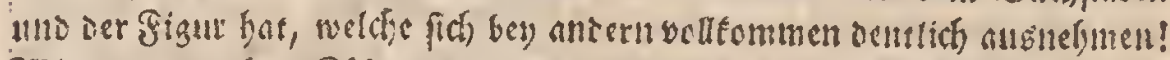
Crzie vou manctiem Saffer, won einerley Gattung oer Sarwen, fino ber Puncte wentgere, als bey ocin andern, weil an oem einen Siffer sween Puncte in efllem infanmen gefoplen, in den andern abee jeder abgefondert ift; ober

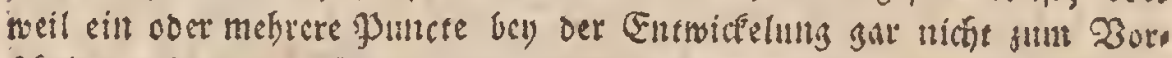
refgeine getommen, fontorn ansgeblieben find, weldge fich bey-einem nit. Dern befinden. Sibie oft findet min Safer, an deren flügel fo gar diefe Verfchiedenther sugleich bemerfet wirb, indem der eine Flígel inchr, der alloere wentiger, diefer abgefonderte, jener bufammen gefofiene, Wuncte

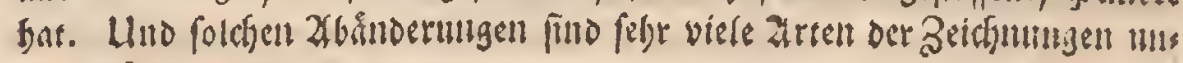
termorfen.

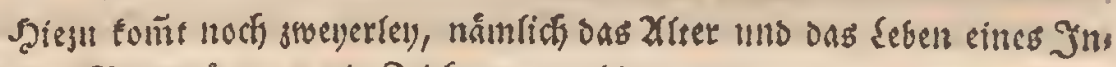
fectes. Bende andern bie Beidjnungen bin uno wieder nicht wenig ab.

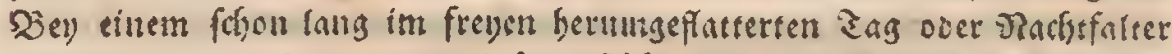

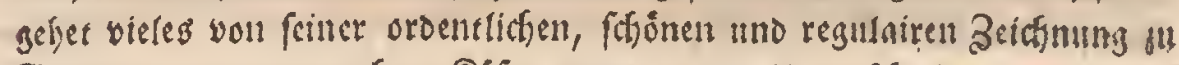
Grunoe; uno an maltefem Rafer, wenn er toot ift, verfdowindet altd mans dhe Beichmung, die ifm, fo lang er lebef, eigen ift.

Jof werde biernils am Ende eine Solge siefsen, beren man ficf bey bet Bentheilnng getwiffer abbiloungen wiro st erinnern baben.

\section{S. 8.

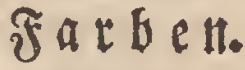

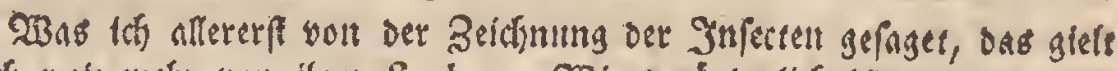
nocf wett mefr von iber farbe. WBie verởnderlich iff an ciner uno eben berfelben Gartung oas mebr uno weniger ountele, kaftige, icb. 
bafte und gleinsende, und zisar gleidi) won ber Wertuandelung. ber.

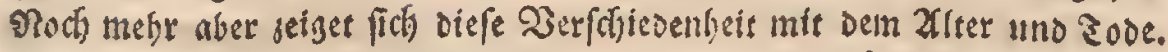

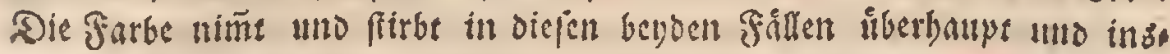
gentein ab. Das Grime verfofieft, dab Gilbe wiro braun, oas 3raune

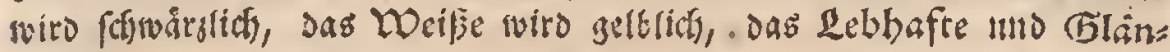
zende notro matt, 11. F. w.

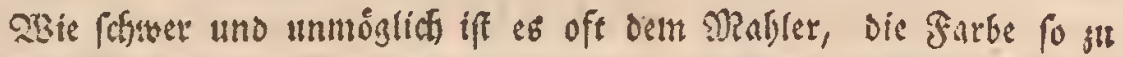

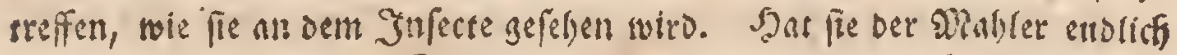
getroffen, fo verdirbt der Sinpferfectier, was jener gut getmaclit; fo und ders

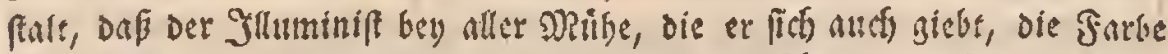

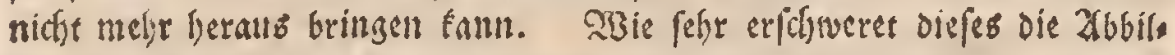

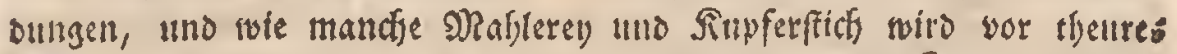

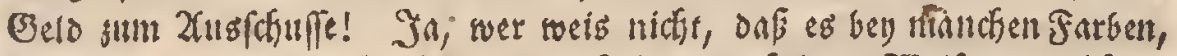

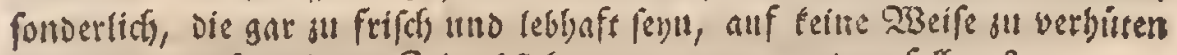

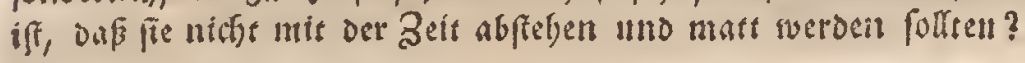

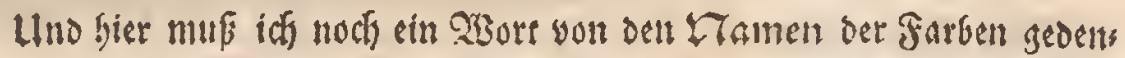

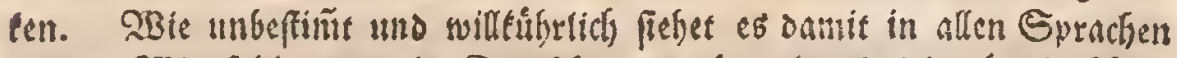

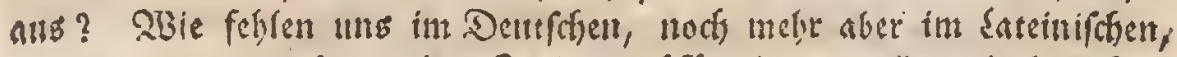

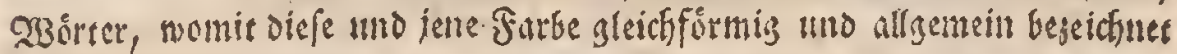

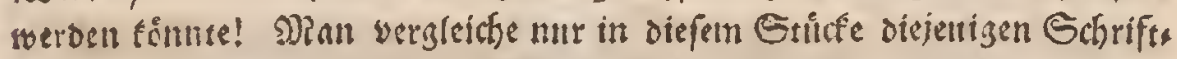
fteller, welche in ifreen Beffiretbungen audf der Farben gedentell, fo wiro

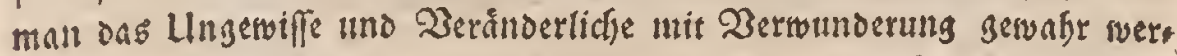

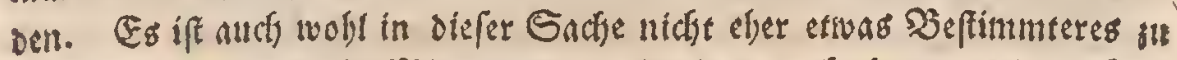

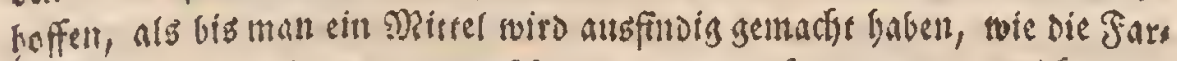

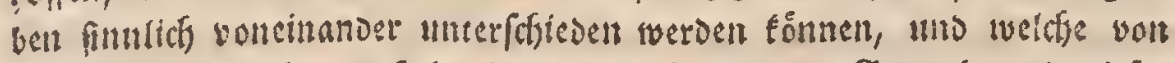

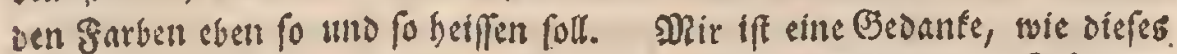
maglith gu machen feinn mointe, vor eintger Beit bengegangen. Sth babe audf fefion ben 2 erfud) diesfalls gemadjt, und es fheint mit allerdings

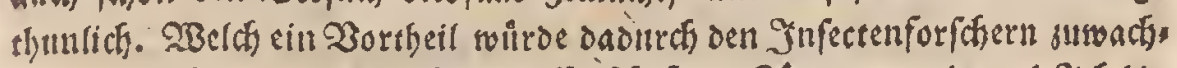

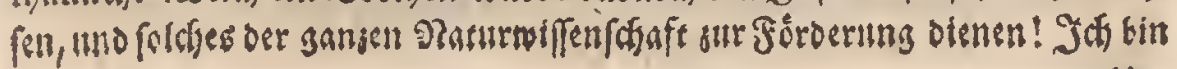




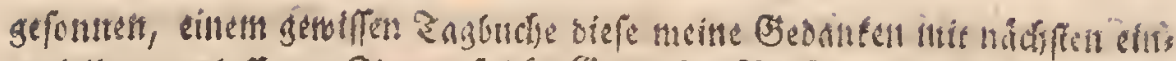

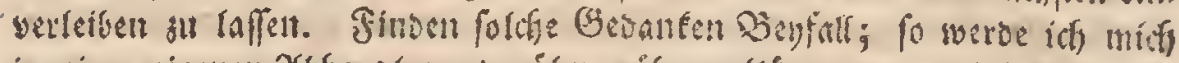

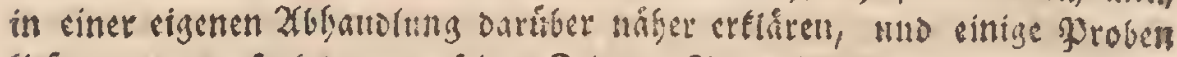

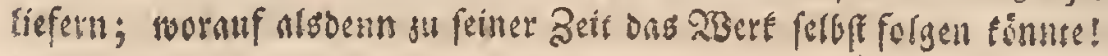

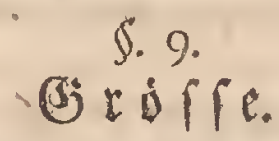

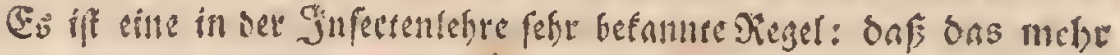

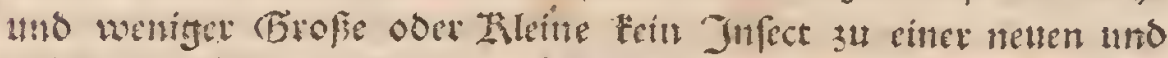

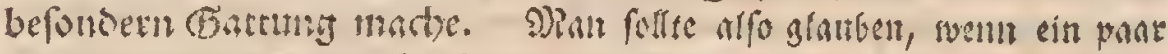

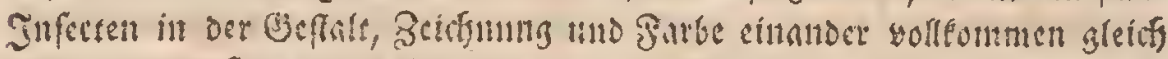

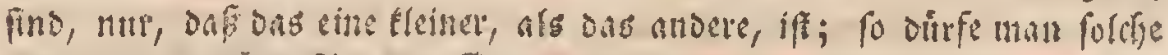

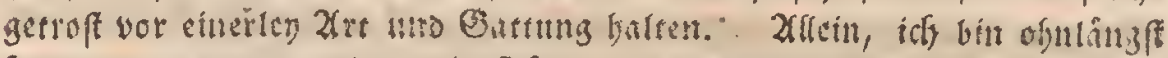

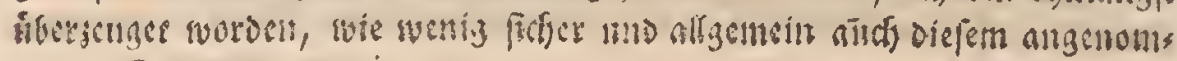
minen Sage utrmint.

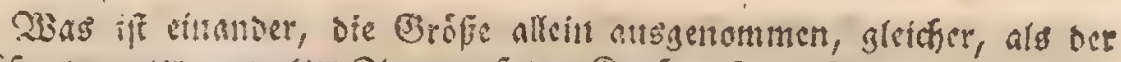

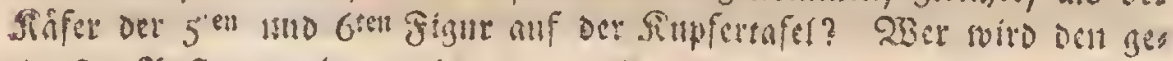

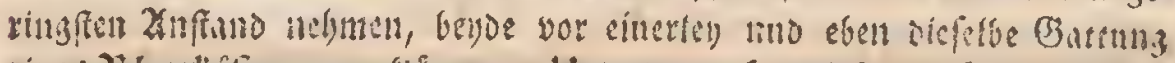

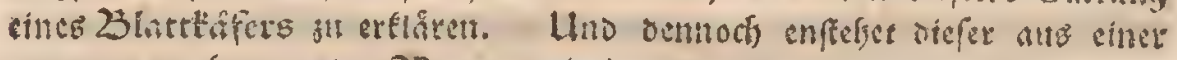

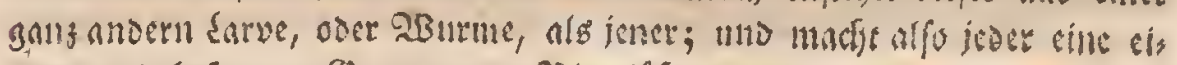

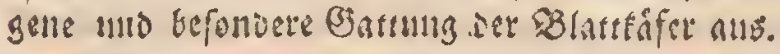

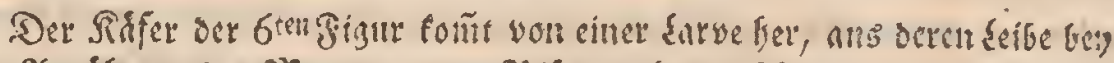

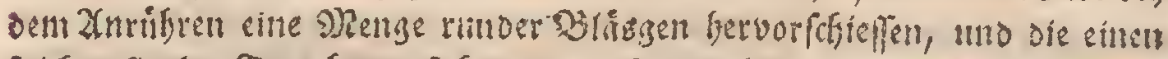
foldjen frarten Bertich von jidf geben, oafi man ibn nidje nut weit mo breit

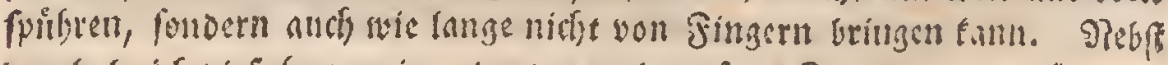

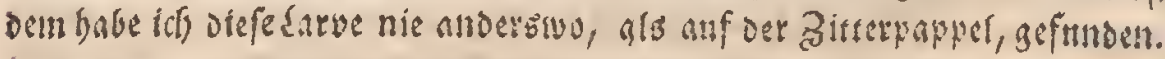

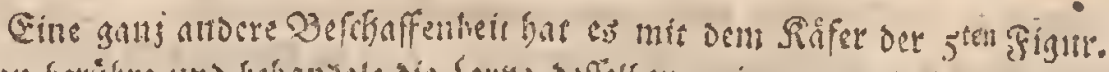

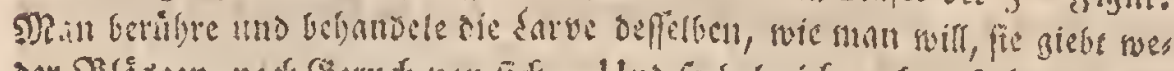

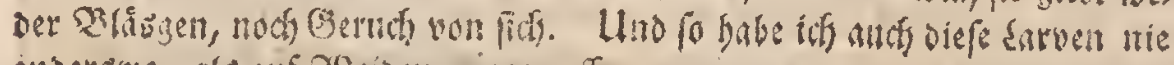
ancerswo, als auf 23 sioen, singerroffen. 


\section{*ers 知}

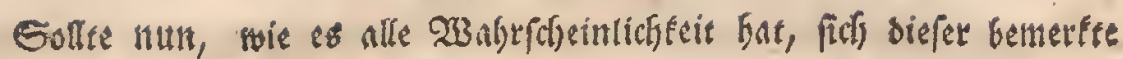

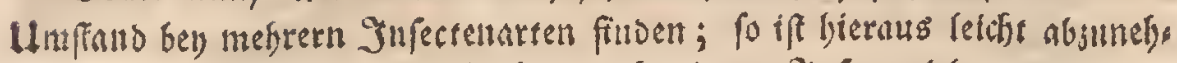
men, wie sweifelbaft uno miflich es noch mit Der Julectenlebre ansitebit; und wis oft ein Snfectenforffer wirs anfeben milfen, ob et von diefem oder jenem Jnfecte eine zbbiloung nefmen foll, over nicht, 1 m weder eille Gattints ooppelt an lieferm, noch anth cine Battung in ubergeben!

\section{IO. \\ $\mathfrak{S}$ á $\mathfrak{t} \mathfrak{t} \| \mathfrak{g}$.}

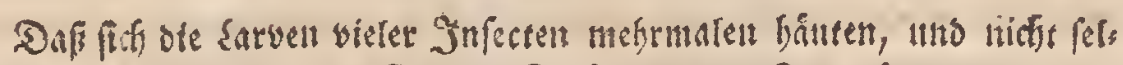

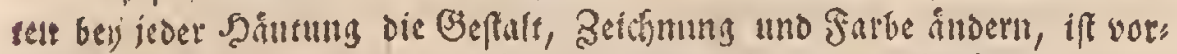

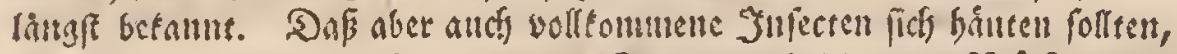

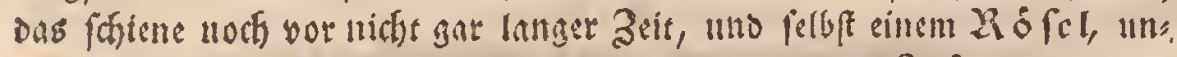

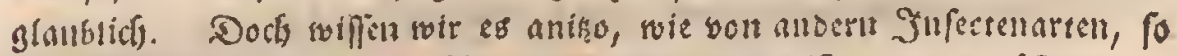

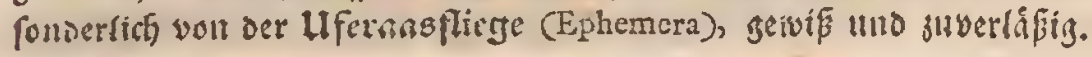

OrBie verlegen madje aber biefes alfs melle biejenizen, welde abbils

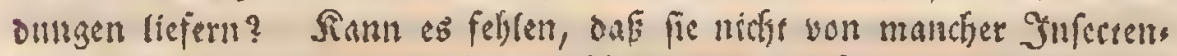

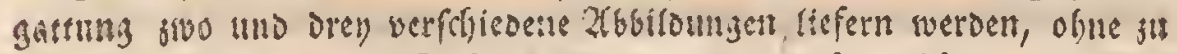

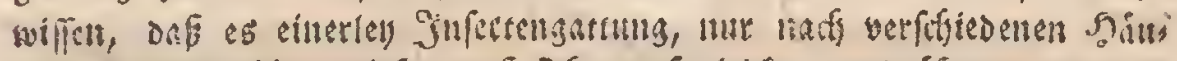

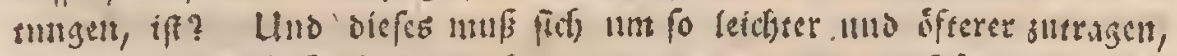

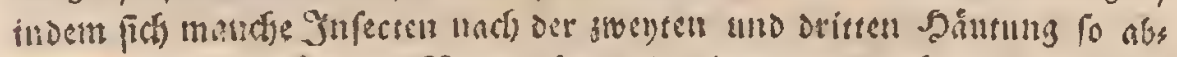

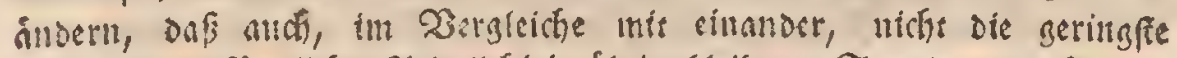

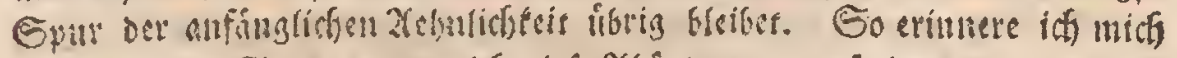

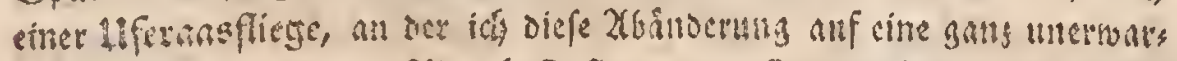

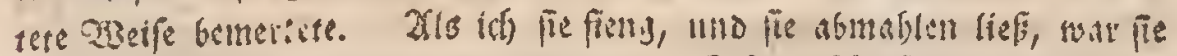

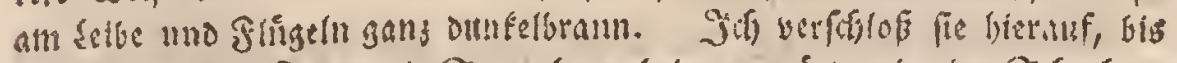

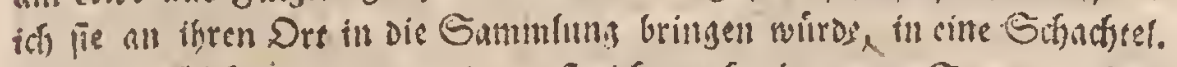

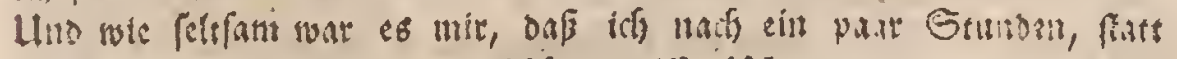

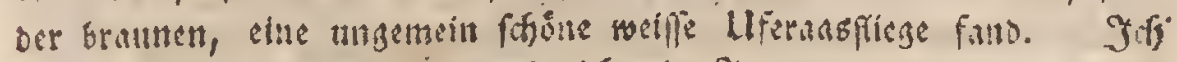

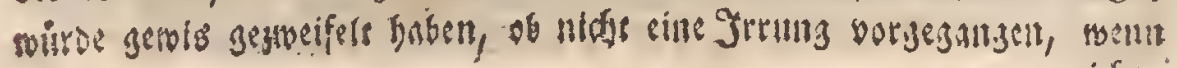
nitifit 


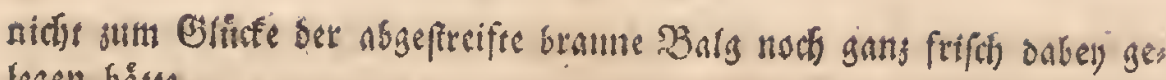
Jegen båtte.

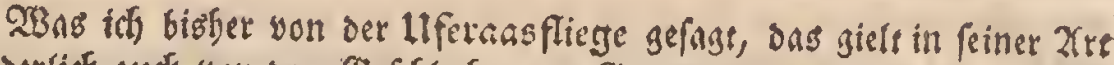

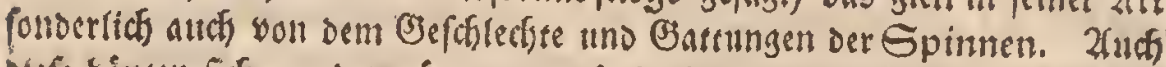

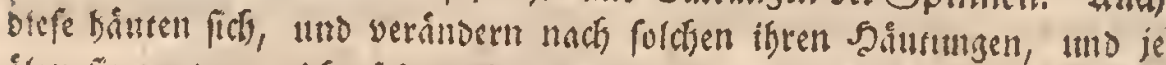
Elter fie werden, nidit feften iffe Beidjunngen tino Sarben. Es iff affo

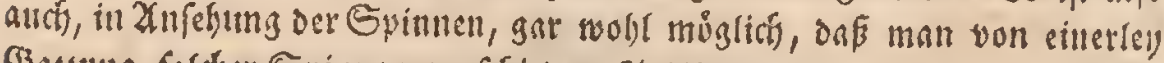

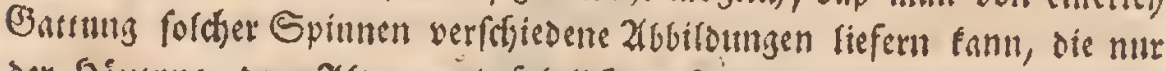

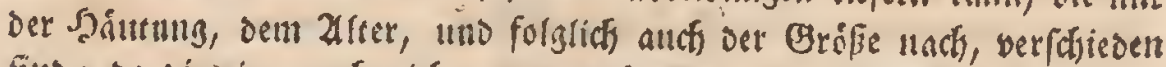

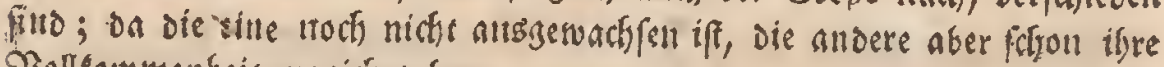
Bollommenheit erreciciet bar.

\section{§. II.

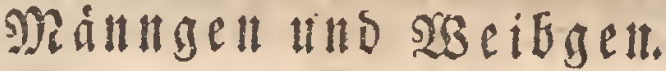

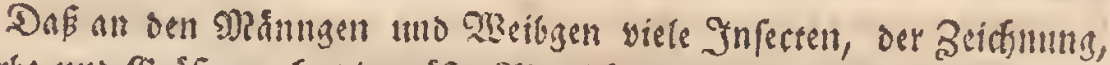

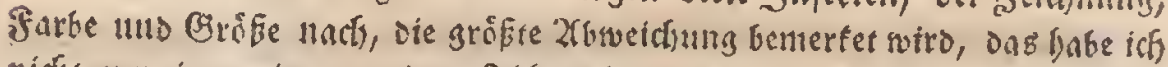

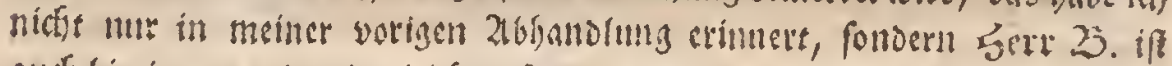
anch bierinnen mit mir gleicher 9Reynumg. SRancfunal aber betrift nucf Diefes nur ganz geringe uno forthe Stricfe, die man wor blofe Bufite ligfeifen adten folfe. So fehen 3.23 . Die beyden 2lfrerbolzanfer ber $7^{\text {ten }}$ und $8^{\text {ten }}$ Figur auf oer Supfertafel einander villig gleich, nur saf

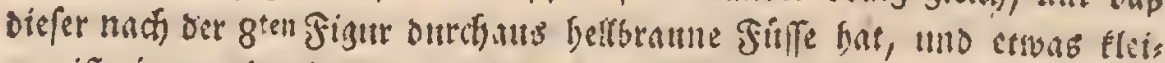
ner ift, jeller aber in ber $7^{\text {ten }}$ Figur an ben Gefente!ll mit foffruirglichent

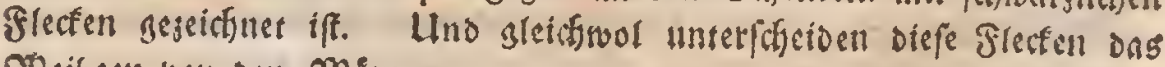
2isciggen bon oem Männgen.

alfein, man twirbe fich fefre irren, wenn man won bergleicfen, atcó

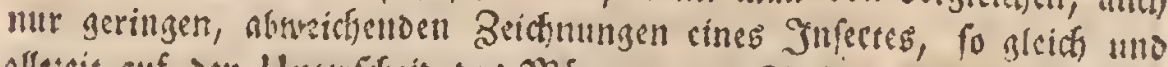

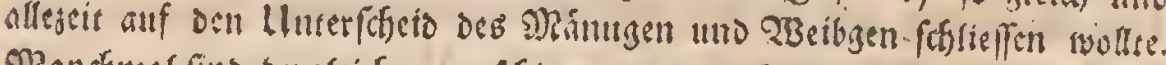

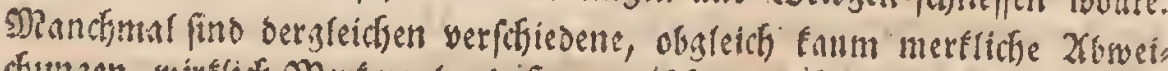

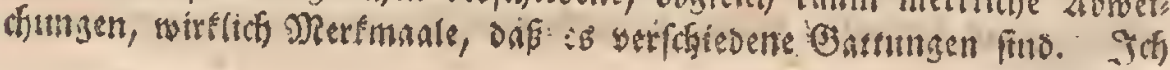




\section{*er}

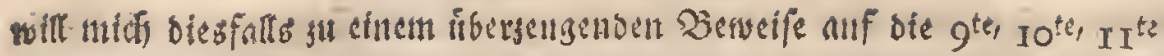

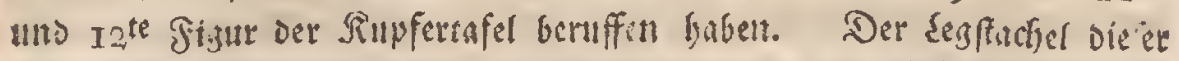

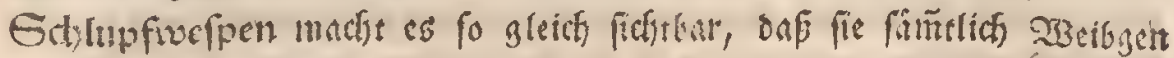
find. Sielyet man fie mut oventyin an, fo folfe man glauben, fie waren

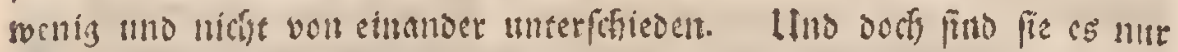

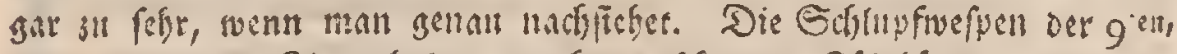

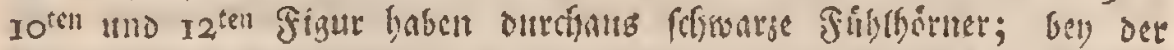

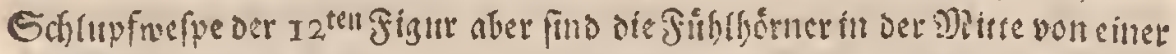

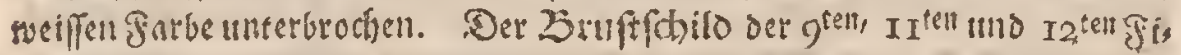

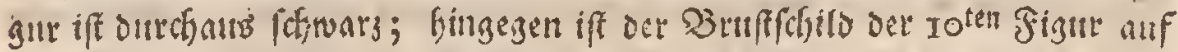
beyden Seiten mit einem weiffen Stridfe cingefapt. Das fublate der

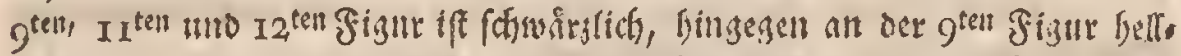

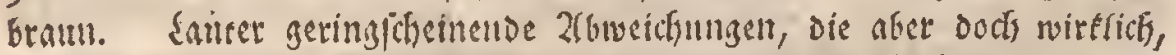

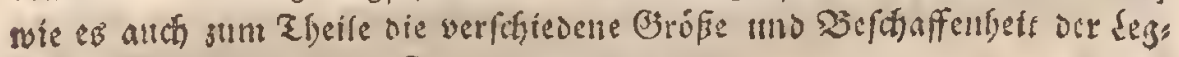
fanchén ervetfet, eigene Gatrungen andonten.

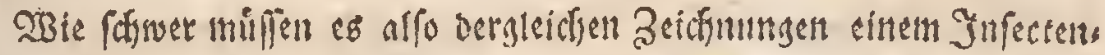
forfcher macisen, weln er abbiloungen liefern foll; indem er, wie ferbon mejemalen gemeloet iff, imner forgen mun, entweoer cinerley Gastungen

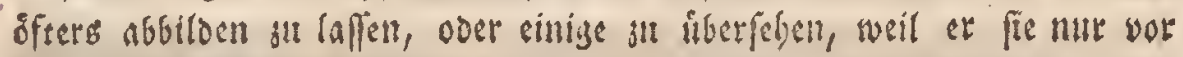
Spielarten gebaltenl bat.

\section{§. I2. Berdreibunget.}

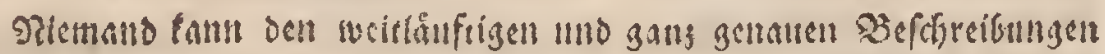

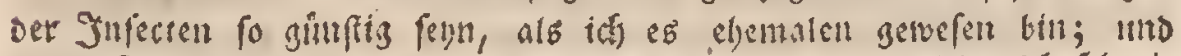

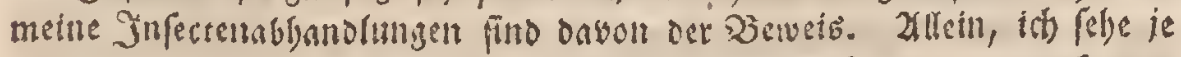

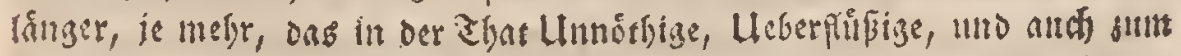
Theile Hnifhere oerfelben ein. Solche befchreibunasen werden inszes mein ume noch cinem cingen Jufecte, fo man eben vor fich but, anfges 


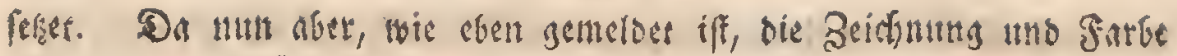

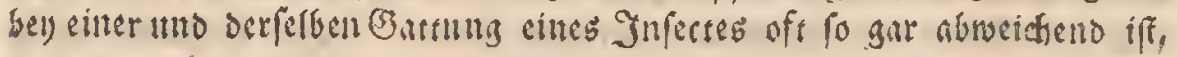
fo tam eilte foldje gar ju genaue $B$ efdreibung nidft anbers, als unvod, fommtten ausfallen, uno wiro mur bey benienigen einjigen Jufecte genatt

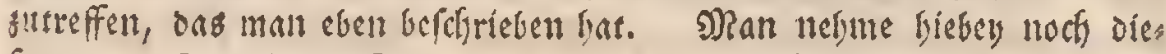
fes an, onfi Dasienige Julect, fo matr eben befdricben, bie und da es"

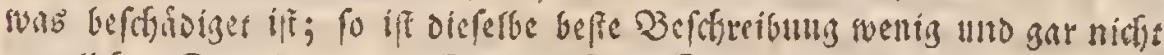

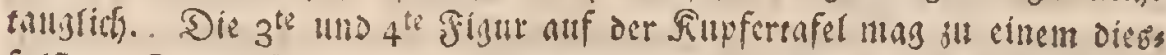

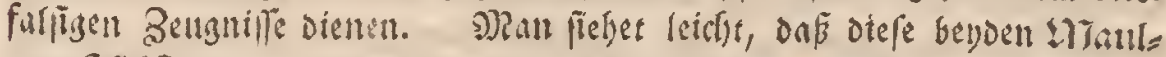
wurfokifer bu ciner nnd eben detfelben Gatung geboren. Xllein, wie gans alloers ift oer Bruffofiro oer $4^{\text {ten }}$ figur, in 2rnfefung oes 23rufts

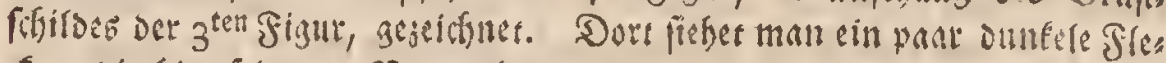

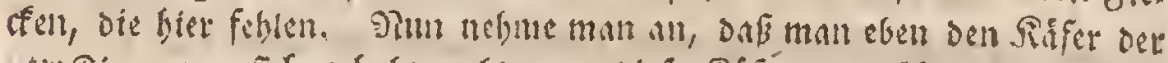

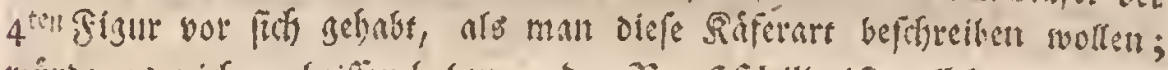

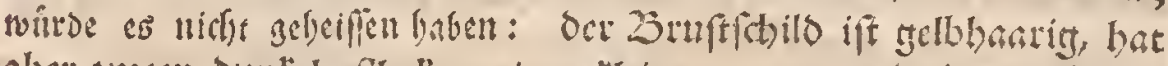
aber 3 wert OunEle flecten, cinch Eleinen nom, uno einen grofferi

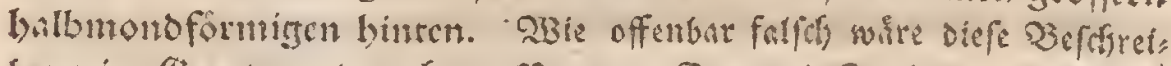

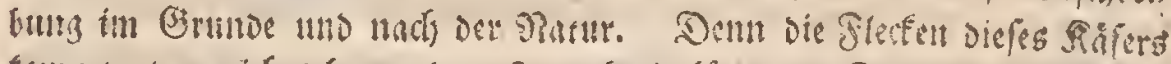

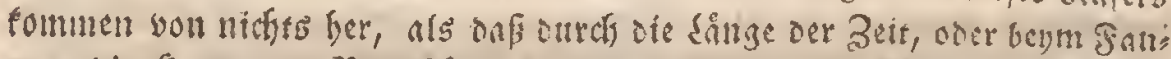

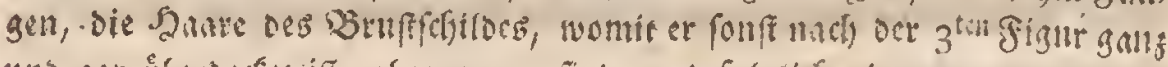

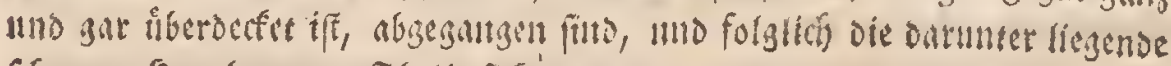

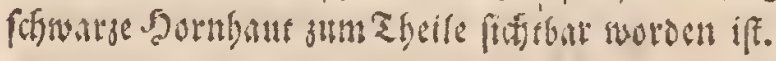

Lino eben, um diefer fo gar tritglidfen Befdreibuntuen foillen, habe

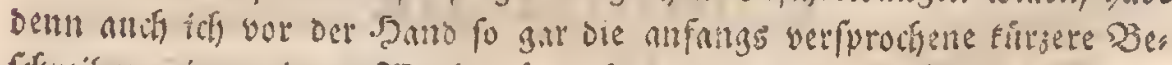

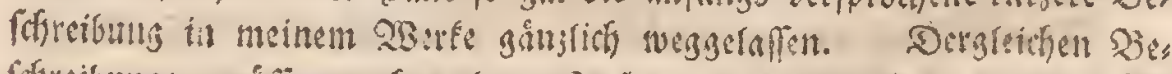

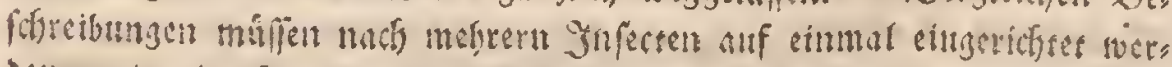

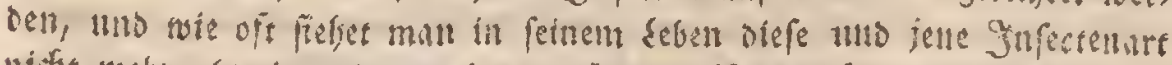

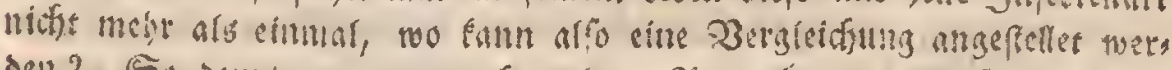

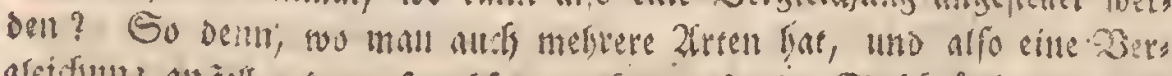

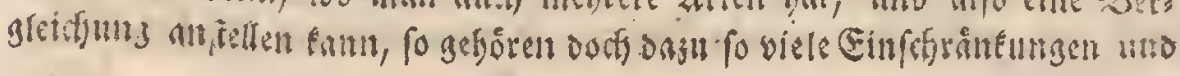


Erinnermigen, als es der bamalige 3ruef oex 2litgabe biefes meines

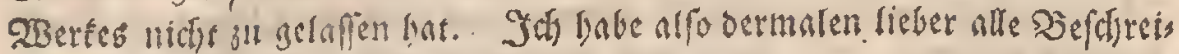
bungen soegrafen, als mangelbafte liefern wollen.

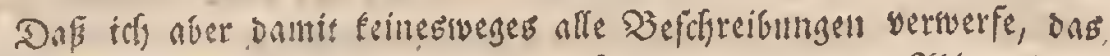

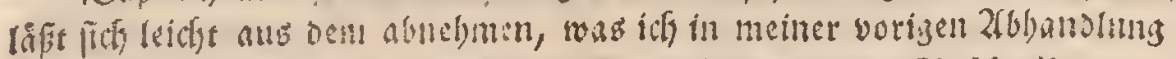

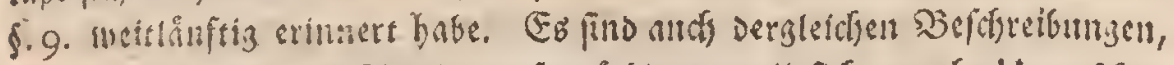

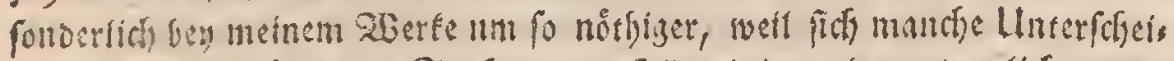

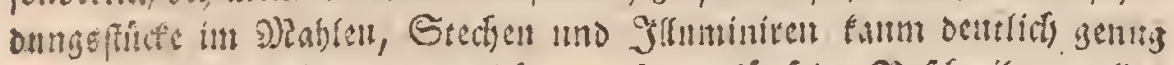

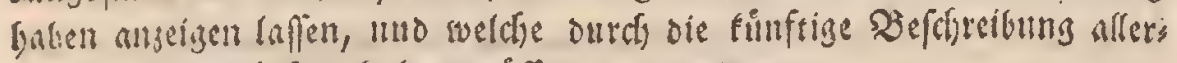
erfe iffe rechtes sicht erbalten miffen uno werden.

\section{I3. S(b) riftererer.}

פonn fomme idf nod anf einell J̧anptmmfent, weldfer die Julectens

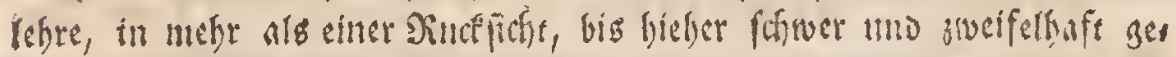
madjt bat. Diefes find de Edyriften oer Jufectenforfefer, mo die $2 \mathrm{Ab}$ bilonngen, oie ung einige derfelben gugleich getiefert baben.

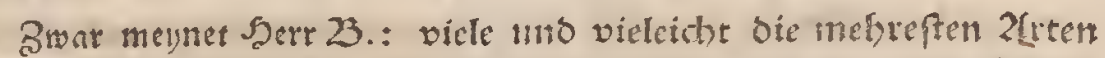
Dex Infecten wâren in ben Gyfenen fo gut bezcid)met tmo fennts lid gemadts, oafiz man bey ibnen nidyt cimmal de Zubilounten vernifie.

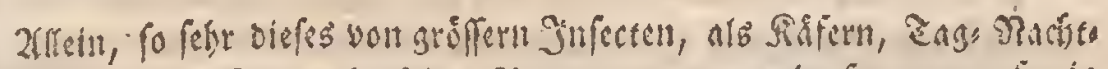

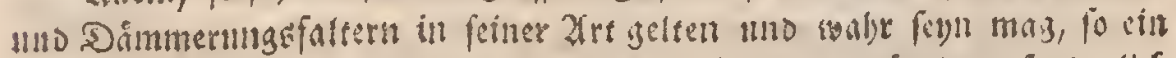
gans anders uno juft ons Bejentheil geiget fich bey Den ibrigen, fondertids

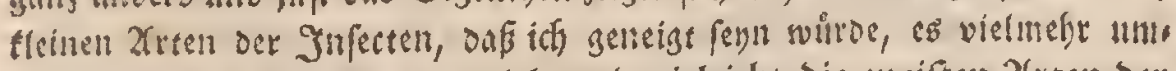

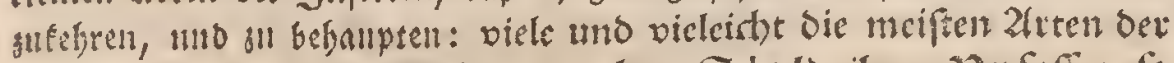
Jnfecter fino in ben Grftemen, obne Sdullo ibrer Detfafier, fo unvolfemmen bezcidinet uno fenntlidy genind), onfj, man obne 


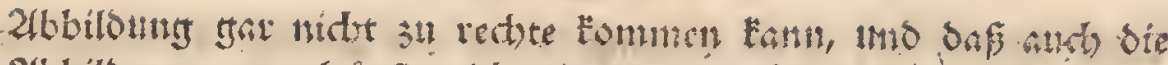
2lbbiloungen gax boufig nidte cinmal ors nóthige Lid)t uno İents

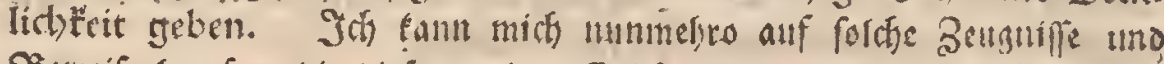

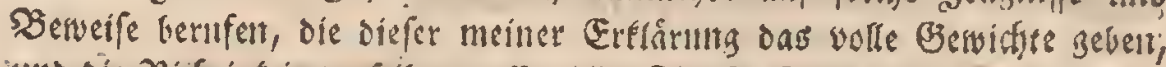

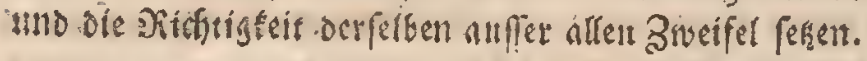

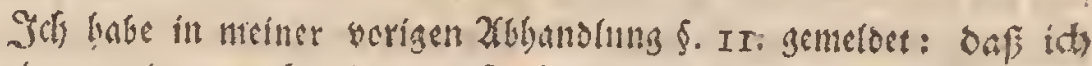

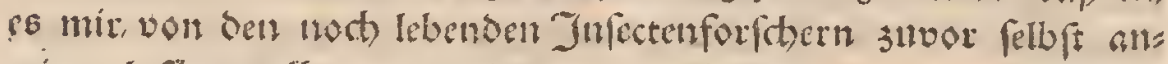

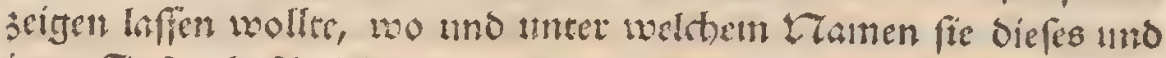

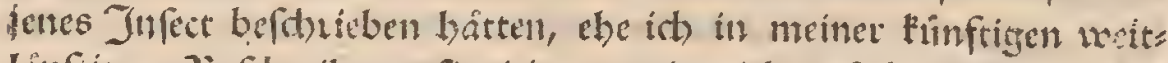

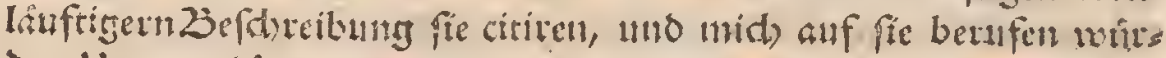

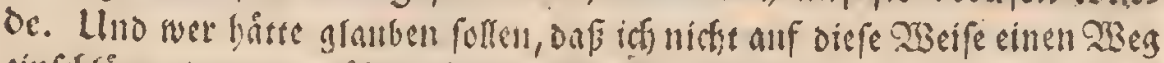

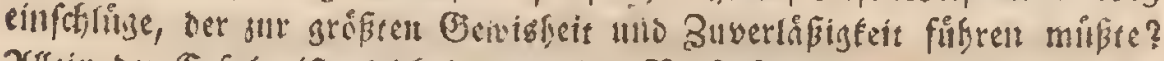

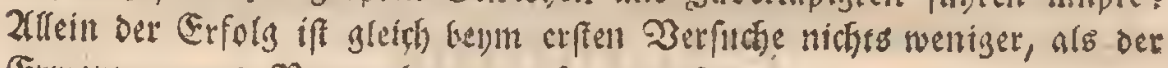

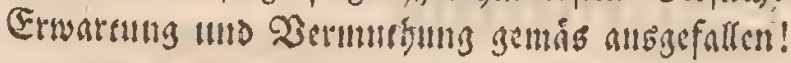

So bulo die fect) e erfen Eaferm meines Jufectenwertes gegen Ende bes vorigen Jabres gefochen waren, fo-lies iof foldje illuminiren, Into

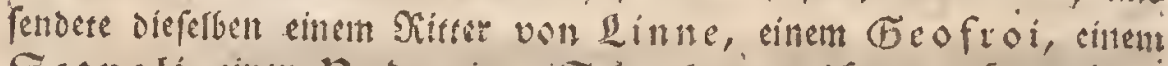

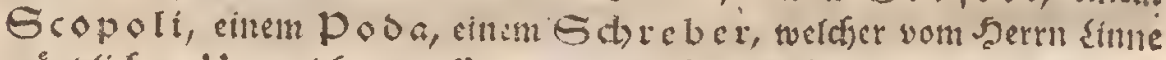

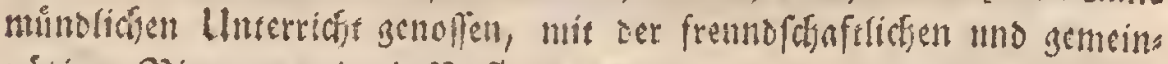

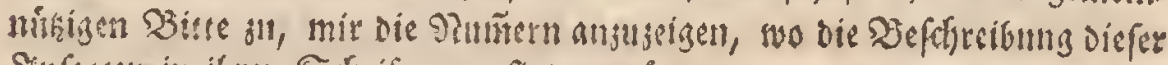
Jinfecten in thren Gdyrifen 311 fitzen wiste.

Diefe beribmen uns gefeliten झRenter bofen midf meiner 3 itte, wos

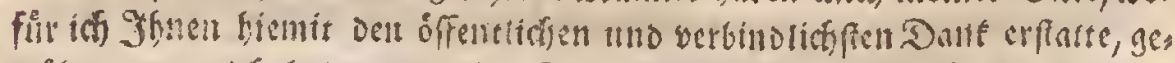

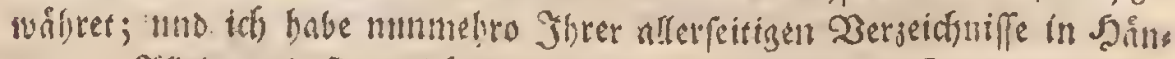

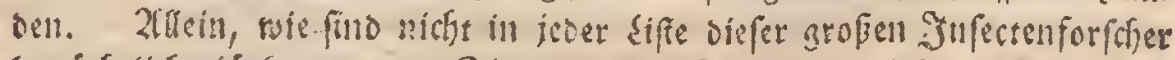

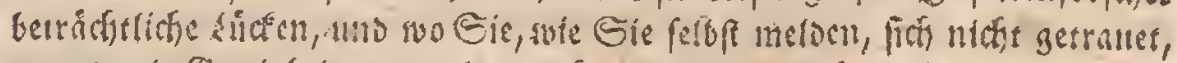

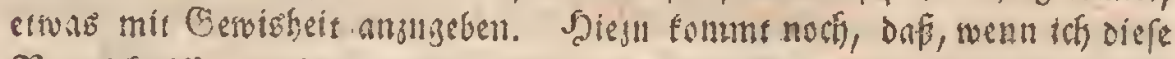

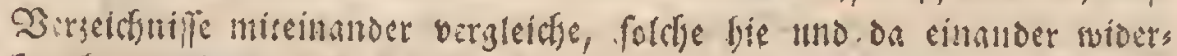
fpredin. Sert von Liune bat oft on eitesicke gernfin, wo Jign cin 


\section{*s n}

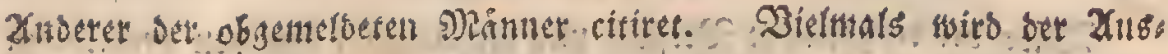

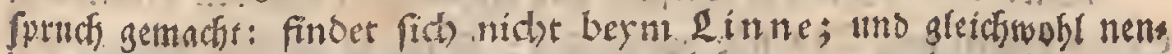

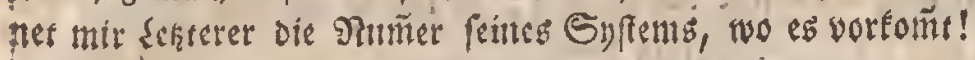

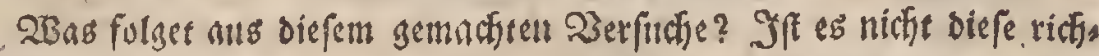
tige Sditnfofolge:

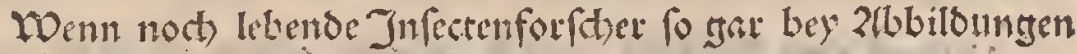

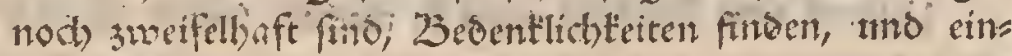
alloet widerfptedten; was wiro erft bey oenentenigen

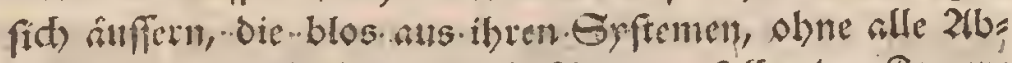
biloungen,: urtheilen uno beftimmen follen: Ferner;

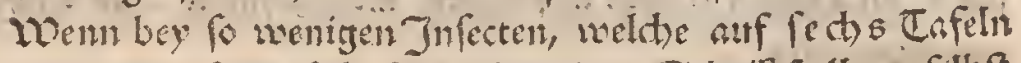

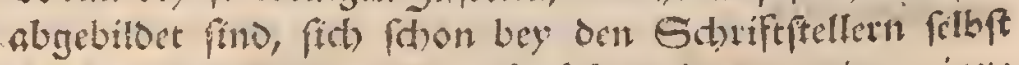

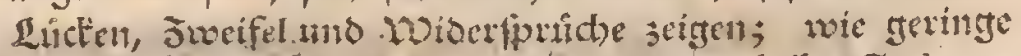

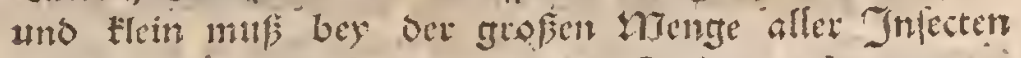

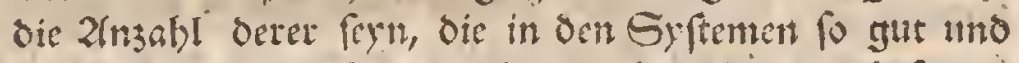
fenntlid gemade fito, oaf man bey thinen and fo gat bie zbbiloungen vermiffer tonnte:

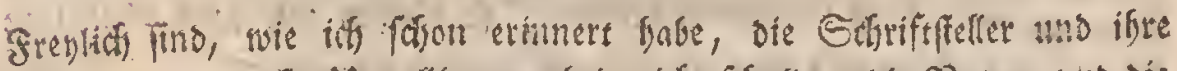

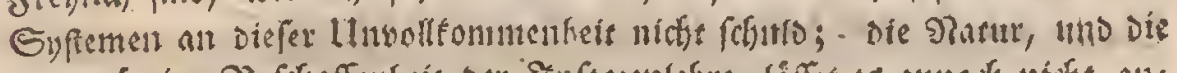

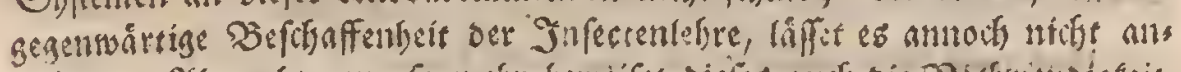

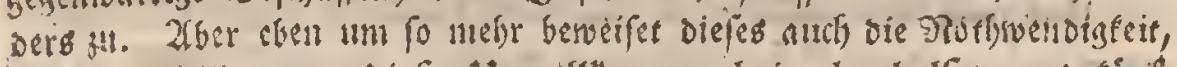

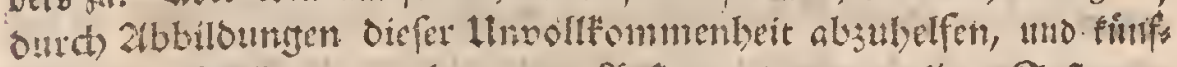

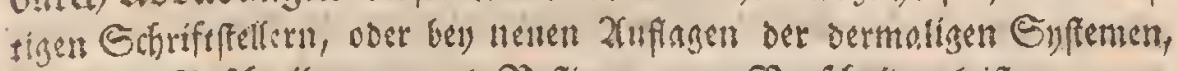

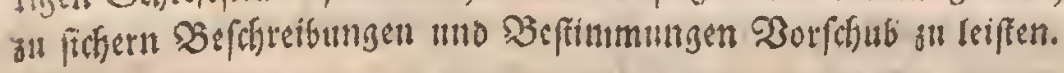

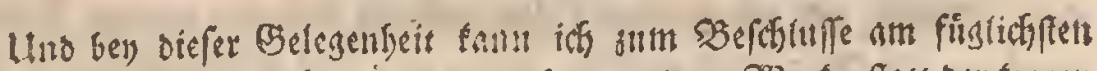

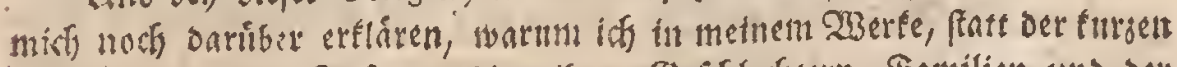
Befotireibung, die Snfecten blos ifren Beffhlectern, Familien und bet: anfir nach angegeren babe. 


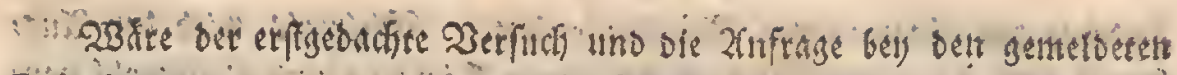

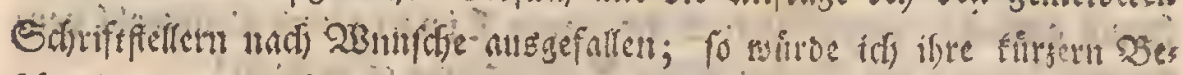

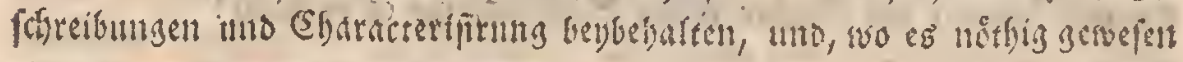

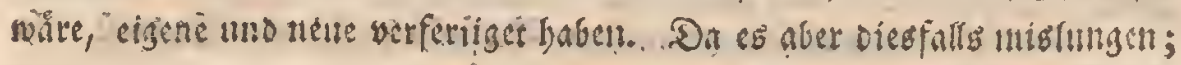
fo mufie iof diefen Gedanten fabren laffen.

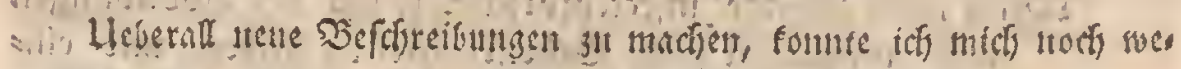

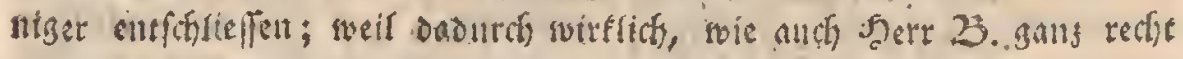

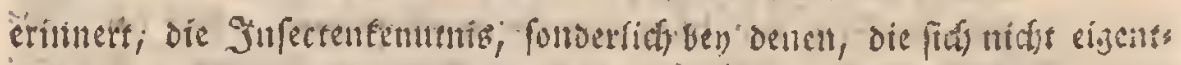

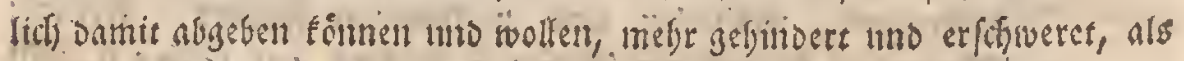
erfeichtert -wird.

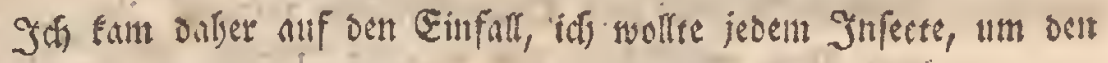

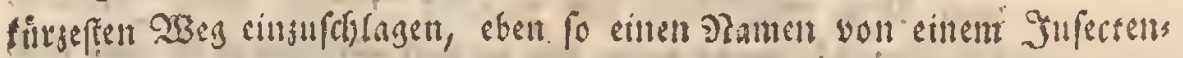
forface, oder andert शantrfinoiger, geben, wie é in oer Sotanic sttr

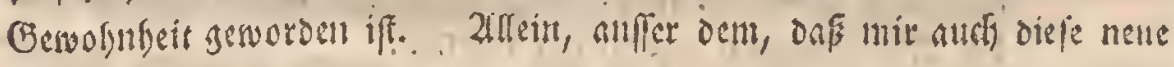

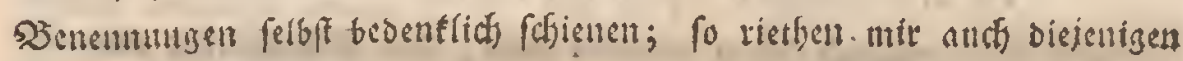

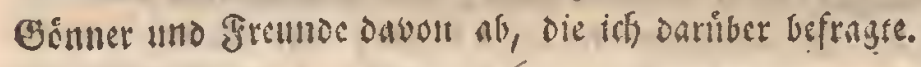

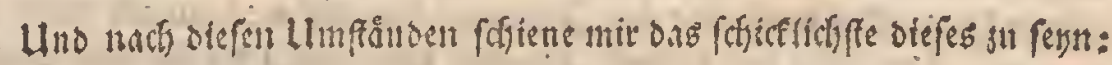

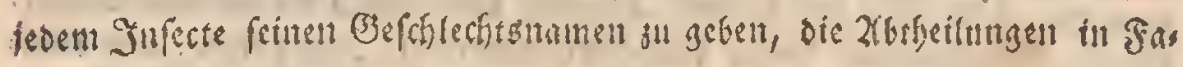

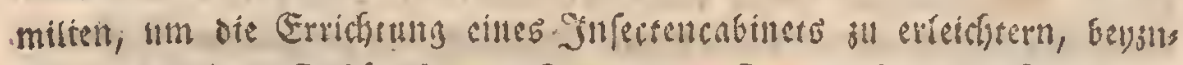

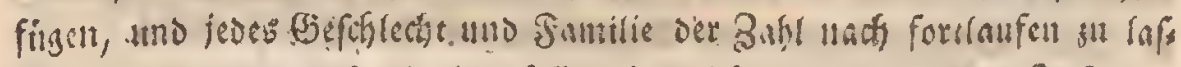
fen. Soiemit, wie idf glanben folle, babe ich mil tuno andern Julectens

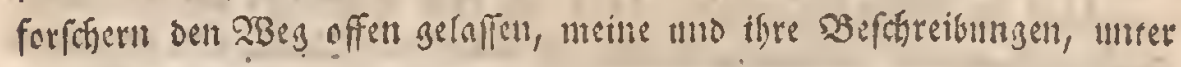

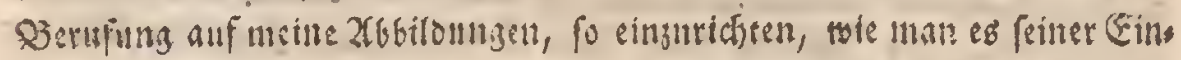
ficti, Beobadianng und erfangten Exfabrumg getmås finden wiro. 


\section{管 \\ $\therefore$ SchI the}

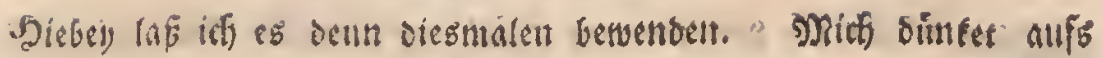

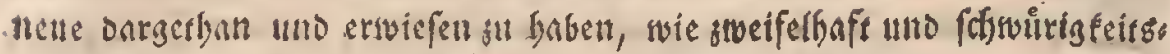

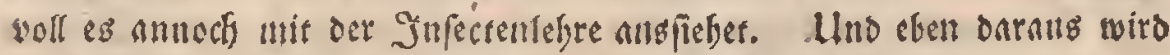

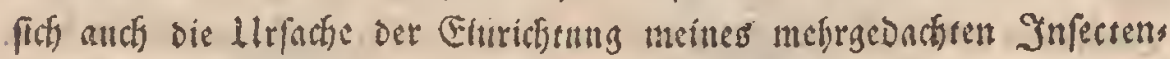

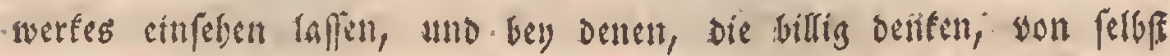
redfffertigent.

Eines Jeffers muf idf unr noch geventen, ber, tch weis nicht

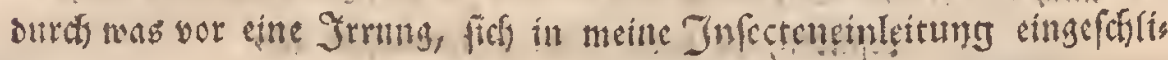

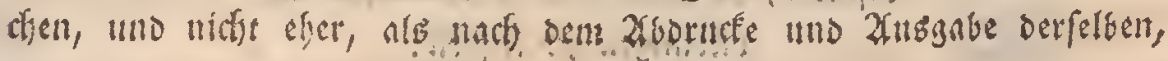
mir offenbar geworden iff.

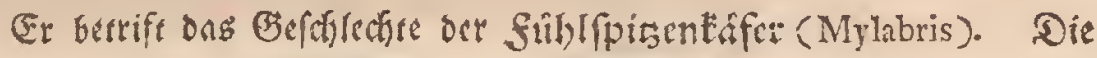

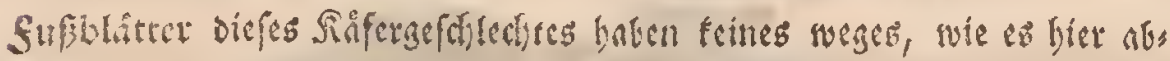

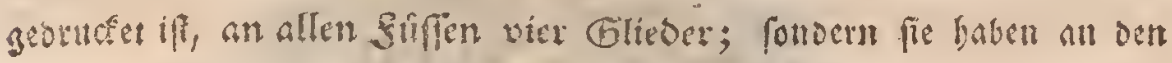

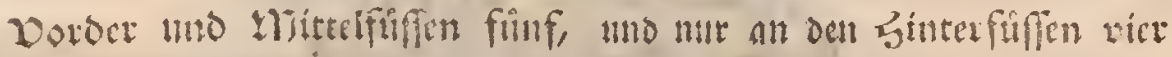

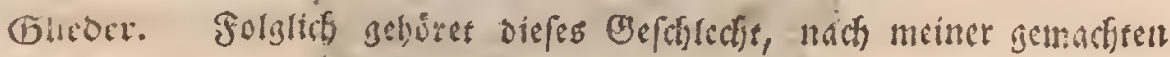

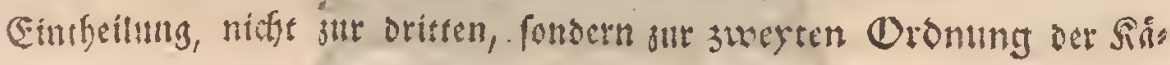
fer mit langlifanligen Slingeldecfen.

Ein nenta, mir tunangenelymes, Zenghin, twie reidit man, bey aller 3orfictit uns Benauistrit, fich itren und feblen fann!

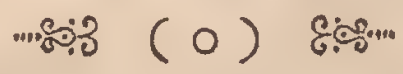




\section{Siacbicfift.}

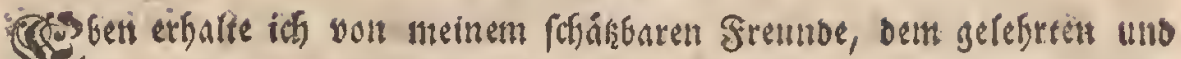

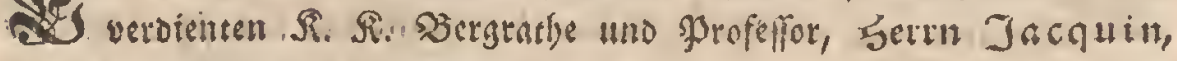
aus Edt)emnits in Ungarth, Die angenehme Nadfricht, suie Er eitte

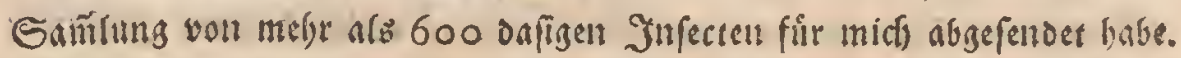

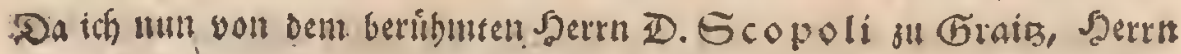

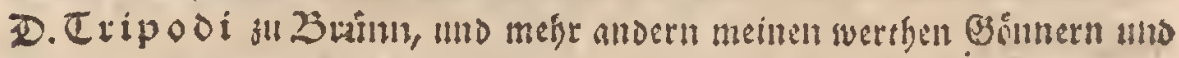
Freunden, gleiches Derfprecten thabe; fo tóntute defes mich veranfafen,

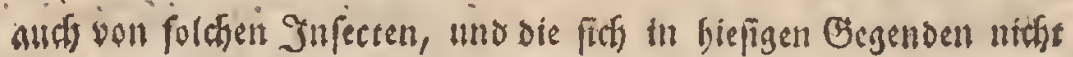

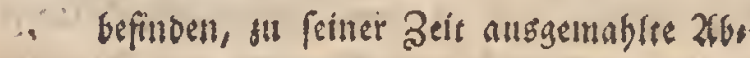
… bildingen bat liefern!

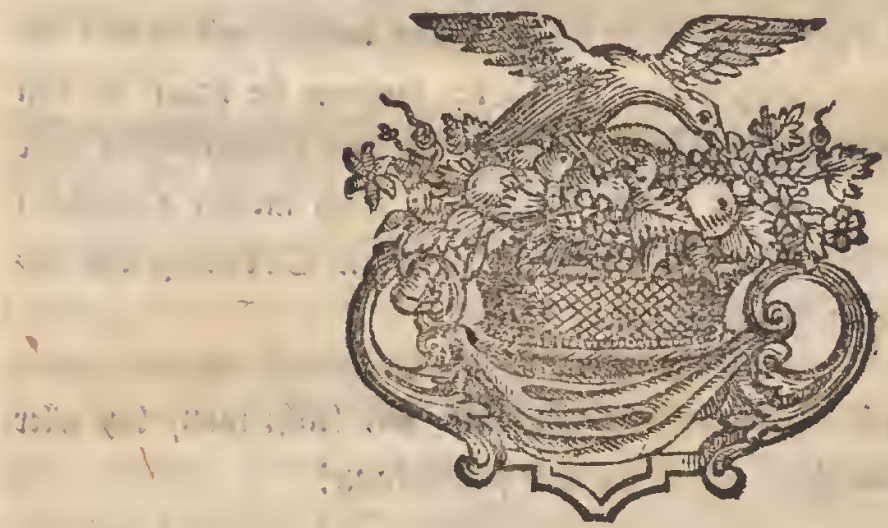


Fig. I. S

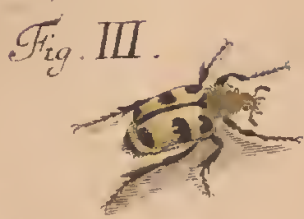

Frg. $V$.
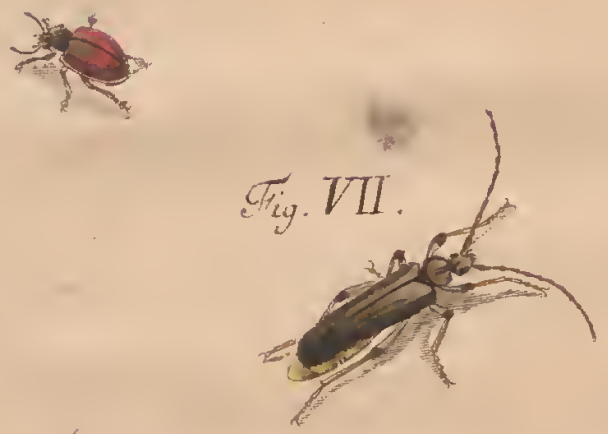

Tre. IX .
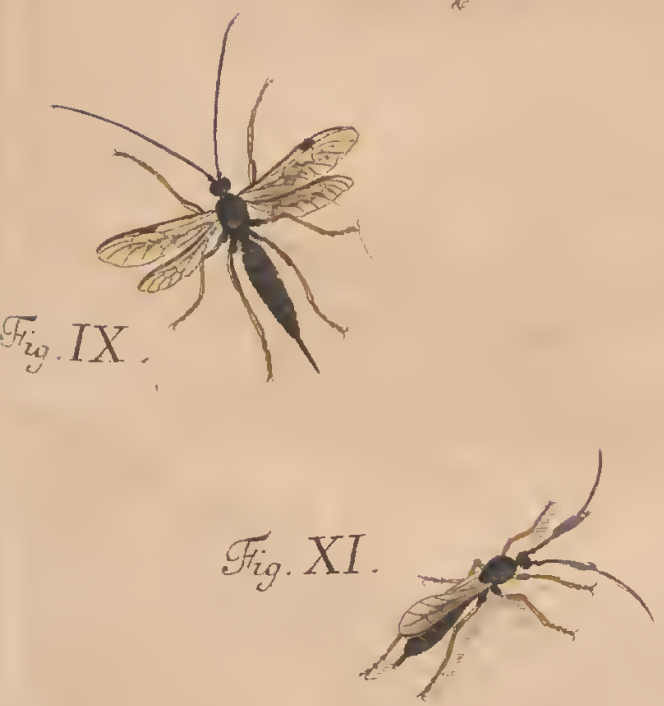

tet p.R.
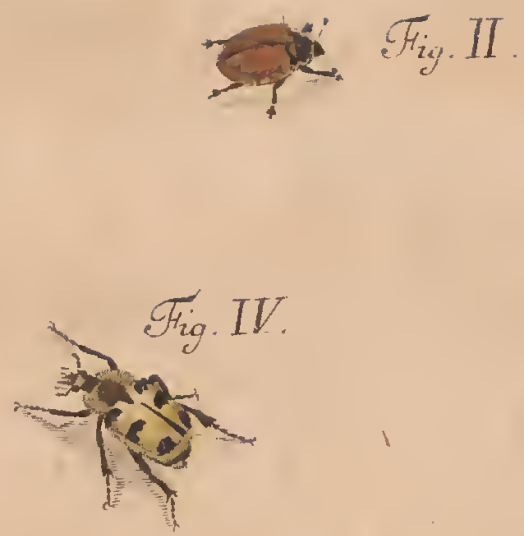

$\mathscr{F}_{\text {rig. }} . V I$.
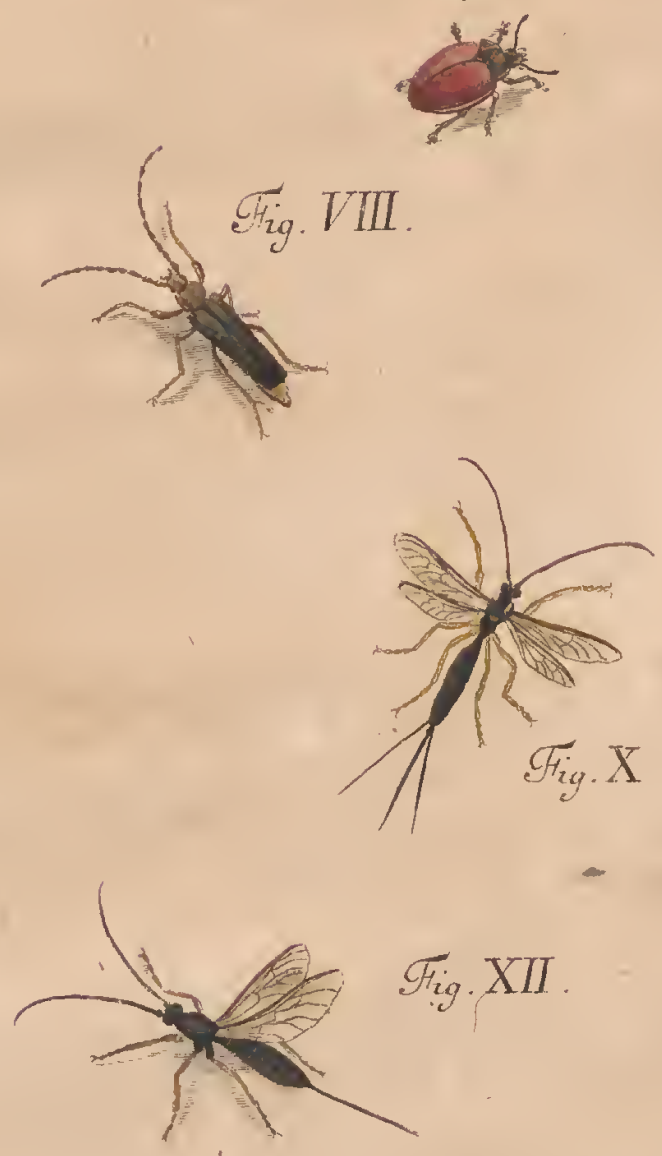

I. G. Fridrich se. Rat 

bo20= 


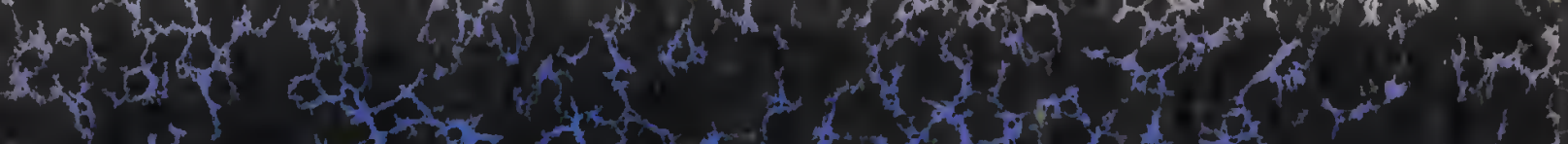
$2 x+2 x^{2}=2,104$

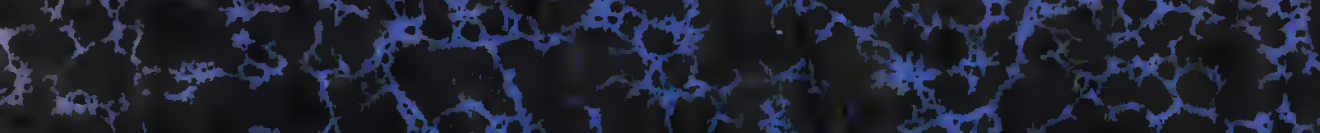

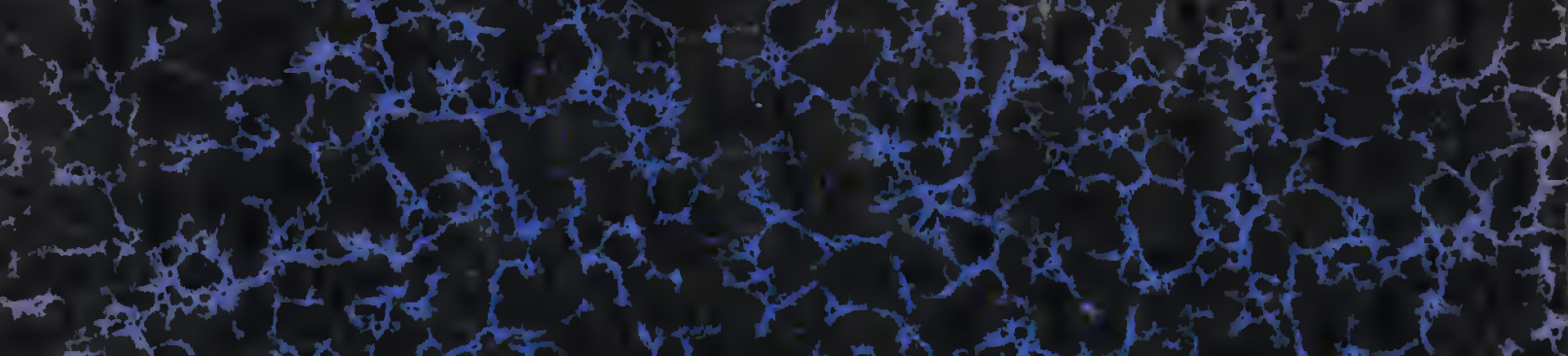

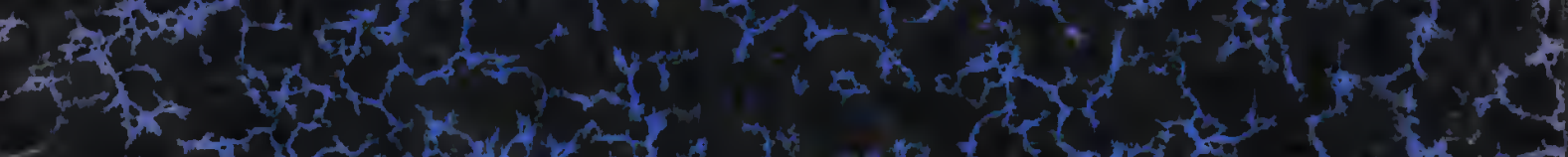
F

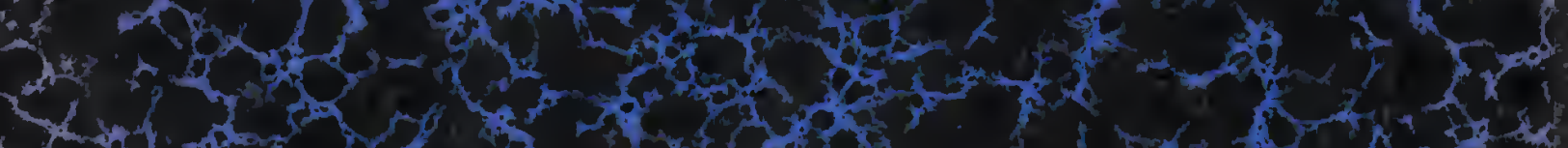
(x)

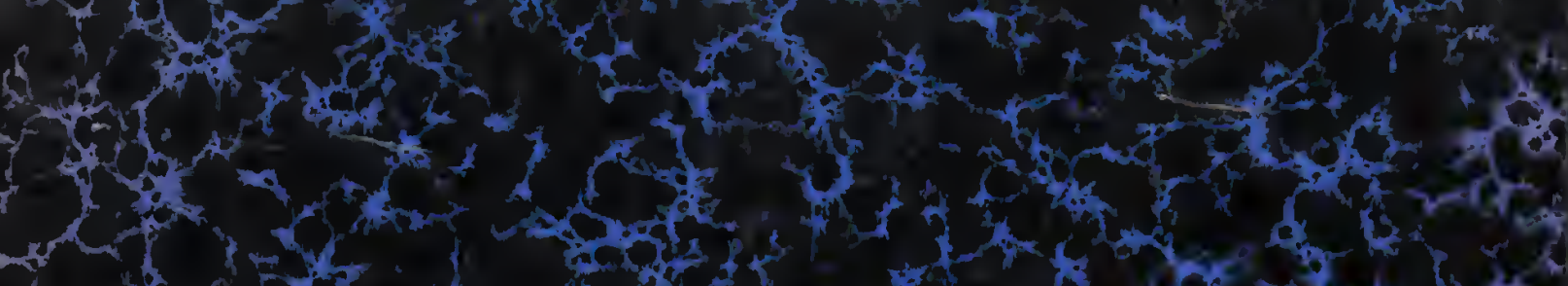

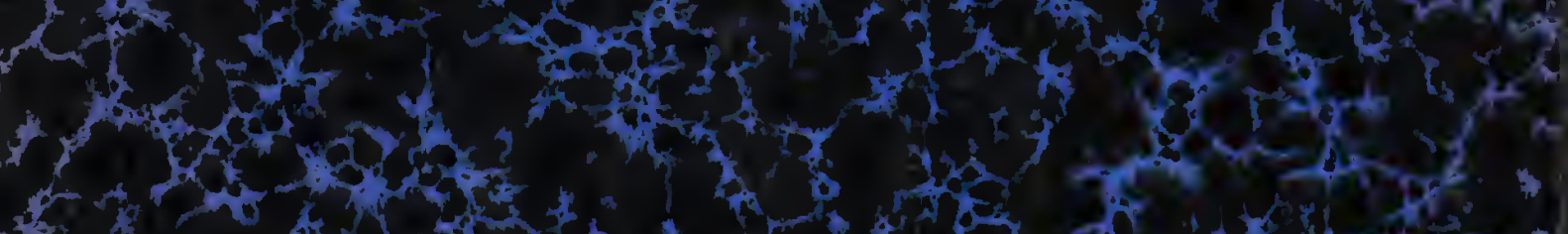

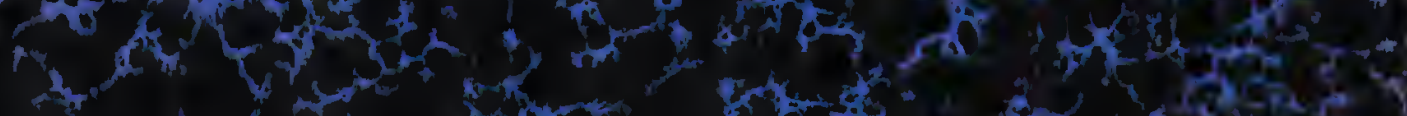
a t

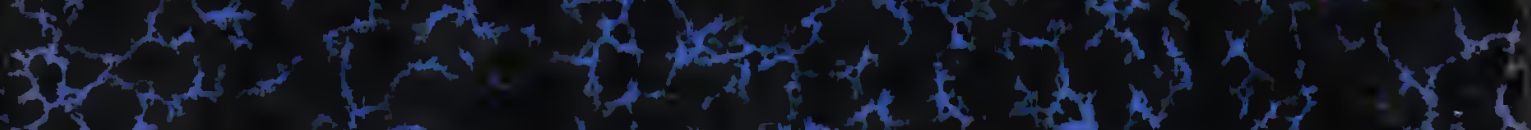

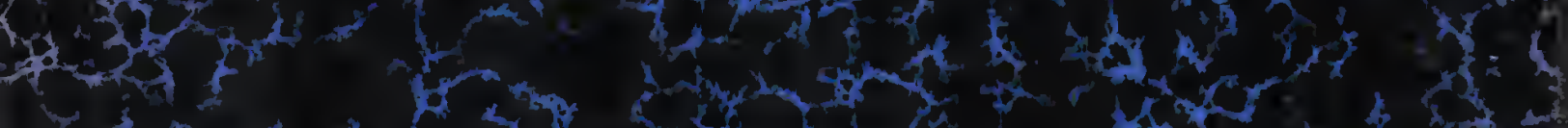

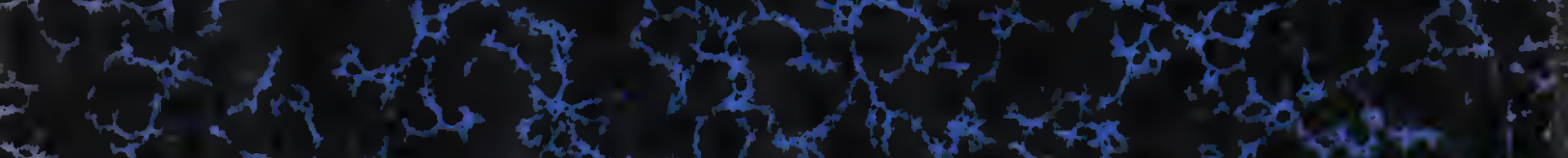

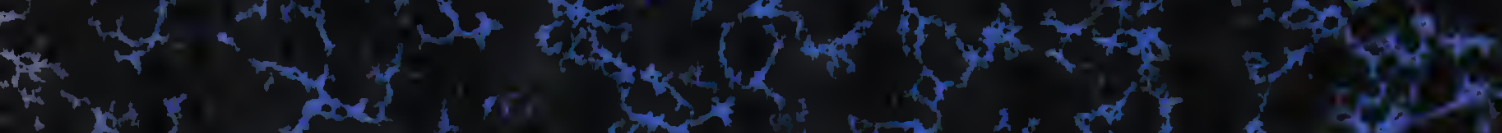

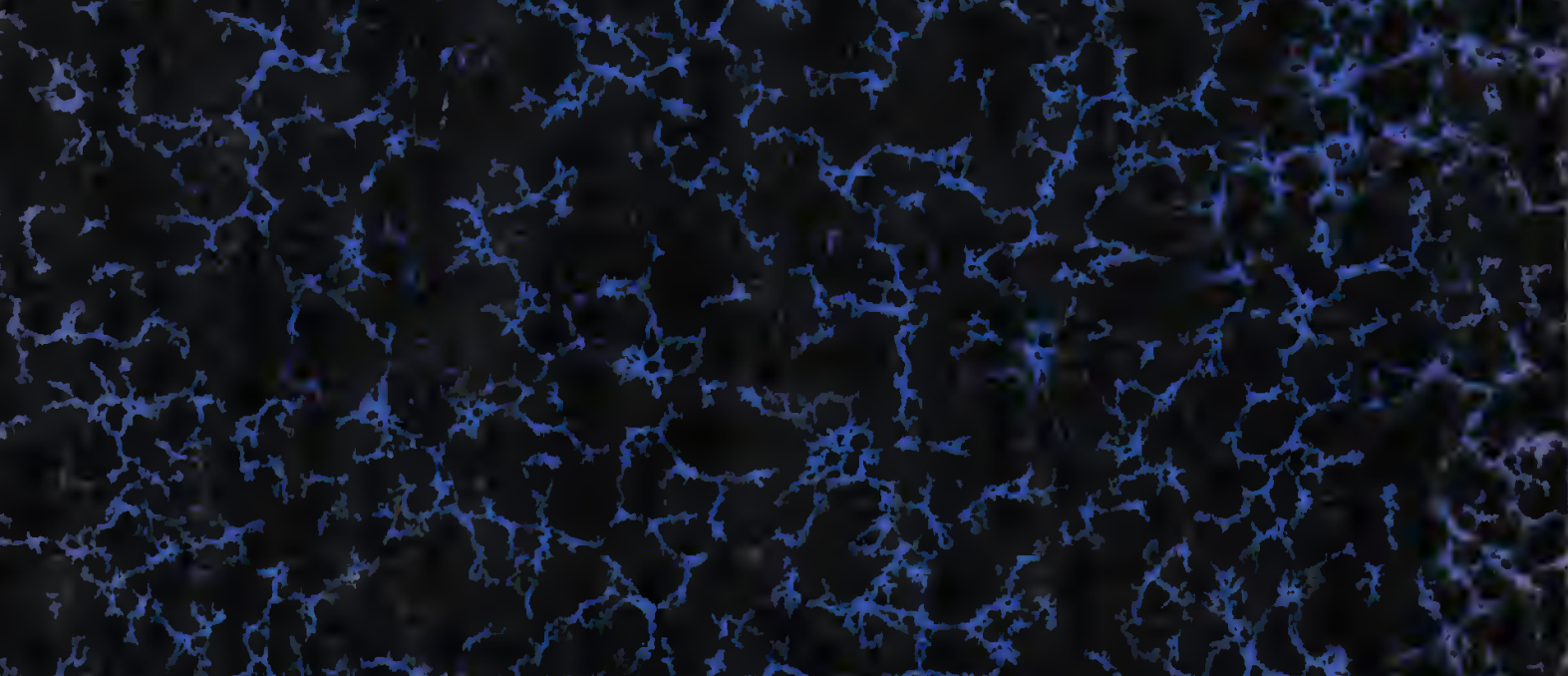
Nos 